\title{
Generation and analysis of a barcode-tagged insertion mutant library in the fission yeast Schizosaccharomyces pombe
}

Bo-Ruei Chen ${ }^{1,2}$, Devin C Hale $2,3,5$, Peter J Ciolek ${ }^{2,4,6}$ and Kurt W Runge ${ }^{1,2^{*}}$

\begin{abstract}
Background: Barcodes are unique DNA sequence tags that can be used to specifically label individual mutants. The barcode-tagged open reading frame (ORF) haploid deletion mutant collections in the budding yeast Saccharomyces cerevisiae and the fission yeast Schizosaccharomyces pombe allow for high-throughput mutant phenotyping because the relative growth of mutants in a population can be determined by monitoring the proportions of their associated barcodes. While these mutant collections have greatly facilitated genome-wide studies, mutations in essential genes are not present, and the roles of these genes are not as easily studied. To further support genome-scale research in S. pombe, we generated a barcode-tagged fission yeast insertion mutant library that has the potential of generating viable mutations in both essential and non-essential genes and can be easily analyzed using standard molecular biological techniques.
\end{abstract}

Results: An insertion vector containing a selectable $u r a 4^{+}$marker and a random barcode was used to generate a collection of 10,000 fission yeast insertion mutants stored individually in 384-well plates and as six pools of mixed mutants. Individual barcodes are flanked by Sfi I recognition sites and can be oligomerized in a unique orientation to facilitate barcode sequencing. Independent genetic screens on a subset of mutants suggest that this library contains a diverse collection of single insertion mutations. We present several approaches to determine insertion sites.

Conclusions: This collection of S. pombe barcode-tagged insertion mutants is well-suited for genome-wide studies. Because insertion mutations may eliminate, reduce or alter the function of essential and non-essential genes, this library will contain strains with a wide range of phenotypes that can be assayed by their associated barcodes. The design of the barcodes in this library allows for barcode sequencing using next generation or standard benchtop cloning approaches.

\section{Background}

Current genome-wide analyses mainly depend on either gene expression profiling or large-scale mutant phenotyping (e.g. [1,2]). Expression profiling allows for the detection of changes in gene expression levels; however, the pattern of gene expression does not always reflect gene function. For example, in a genome-wide analysis of the budding yeast Saccharomyces cerevisiae gene deletion mutant set, less than $7 \%$ of the genes that showed increased mRNA expression in response to four different conditions were required

\footnotetext{
*Correspondence: kwr4@case.edu, rungek@ccf.org

'Department of Genetics, Case Western Reserve University School of Medicine, 10900 Euclid Avenue, Cleveland, OH 44106, USA

${ }^{2}$ Department of Molecular Genetics, Cleveland Clinic Lerner College of Medicine at CWRU, 9500 Euclid Avenue, NE20, Cleveland, OH 44195, USA Full list of author information is available at the end of the article
}

for growth under the same conditions, and deletion of some of the most highly expressed genes had no effects on cell proliferation. In addition, many genes necessary to maintain normal cell fitness under these treatments did not have significantly altered expression levels [2].

Large-scale mutant phenotyping monitors changes in mutant fitness or other visible traits, and provides direct assessment of the requirements of genes under specific conditions. The availability of the open reading frame (ORF) deletion mutant collections in the budding yeast S. cerevisiae and the fission yeast Schizosaccharomyces pombe has proven to be advantageous in this approach. The principal challenge in large-scale phenotyping is distinguishing individual mutants. The current method of choice is to tag each mutation with a unique DNA

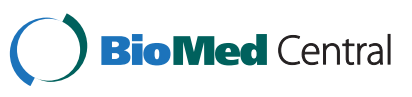


sequence called a "barcode" [3,4]. Because barcode tags are part of the mutations, the proportion of an individual barcode reflects the proportion of that barcode-associated mutant in a population. Thus, following barcode frequencies can identify mutants with a desired growth phenotype from a population of diverse mutants, an approach referred to as parallel analysis $[3,4]$.

An advantage of parallel analysis of barcoded mutants is that mutations causing deleterious or weak phenotypes can be efficiently detected. For example, to identify virulence genes in Salmonella typhimurium, mice were infected with a $S$. typhimurium mutant library where each mutant carried a unique $40 \mathrm{bp}$ barcode tag. The barcodes that were lost from the post-infection population identified the genes required for virulence [3]. This approach has also been extended to cultured human cells using barcode-tagged cDNA and shRNA libraries to discover genes whose overexpression and down-regulation could suppress cancer cell growth and survival $[5,6]$. In all three screens, the mutants of interest diminished in the population but could be revealed by detecting the loss of their associated barcodes by DNA arrays $[3,5,6]$.

The budding yeast $S$. cerevisiae is the model organism where barcode-tagged mutagenesis has been the most successfully exploited [2,4,7]. Its small, sequenced and well-annotated genome and the efficient gene deletion techniques allowed the production of a collection of complete ORF deletion mutants where each deletion mutant is tagged by two unique barcodes [2]. The barcodes can be amplified en masse by PCR to generate probes for commercially available high-density microarrays to take a "census" of the relative abundance of each mutant in a culture under a variety of conditions [2]. Two independent genetic screens using this barcode-tagged deletion mutant set have identified many genes whose deletion caused lengthened chronological lifespan as detected by an increase in the abundance of the long-lived mutant barcodes [8,9]. As long-lived mutants and mutants with normal lifespan are often morphologically indistinguishable, the barcode approach to monitor the length of lifespan of many mutants in parallel demonstrated the power of parallel analysis for detecting weak phenotypes.

S. pombe is an important model system that has many of the advantages of S. cerevisiae, including a sequenced genome and well-established microbiological, genetic and molecular biological approaches $[10,11]$. Unlike S. cerevisiae, $S$. pombe shares a number of similar features with mammals including RNA interference, aspects of RNA splicing and the requirement for the mitochondrial genome for survival of wild type cells [12-16]. A barcode-tagged deletion strain set for S. pombe, in which each deletion mutant carries two barcodes, has also been developed recently [17].

Most of the mutants in the S. pombe and S. cerevisiae ORF deletion sets are null mutations, and haploid mutants lacking essential genes are not present. Truncated essential proteins with partial or altered function and mutated alleles of essential genes with reduced expression levels have been shown to produce viable and detectable phenotypes such as changes in transcriptional silencing and lifespan $[18,19]$. Therefore, a mutant collection generated by a different approach that includes mutations that impair the function of essential and non-essential genes would be beneficial for parallel analysis of phenotypes and genomewide screens.

An alternative mutagenesis method in S. pombe is nonhomologous recombination-dependent integration of a selectable marker $[20,21]$, which can generate a wide variety of mutations. Insertions in the coding sequences can produce truncated proteins with either no or altered function. Insertions in the 5' and 3' region of a gene can change protein expression levels by compromising promoter function and mRNA stability, respectively $[18,22,23]$, and produce viable mutations in essential genes [18]. Previous studies in $S$. pombe characterized two classes of transformants when cells were transformed with linear DNA that had limited or no homology to the genome $[24,25]$. One class of transformants contained single or tandem copies of linear DNA stably inserted in the genome, and the insertion events were often accompanied by deletions in the integrated DNA vectors and adjacent genome sequences. The distribution of insertions in the genome appeared random $[24,25]$. The other class, which constituted the majority of the transformants, maintained the transfected DNA as unstable, extrachromosomal circular DNA despite the absence of a known origin of DNA replication in the vector [20,21,24-26].

Chua et al. [20] and Davidson et al. [21] used this approach to create random $S$. pombe mutants by transforming a $\sim 1.7 \mathrm{~kb}$ DNA fragment containing the $\mathrm{rra}^{+}$gene into strains with the ura4-D18 mutation, a deletion that removes the sequences homologous to the $1.7 \mathrm{~kb} \mathrm{ura}^{+}$ DNA from the genome. These studies revealed two important features. First, only one insertion event was identified in each mutant by the criteria of Southern blotting. Thus, it is possible to generate a library of transformants where each individual contains a single mutation [20,21]. Second, many of the transformants contained insertions composed of multiple full or partial copies of the vector at each site. The complex structure of these insertions made mapping their genomic locations challenging [21].

To facilitate genome-wide functional analysis in $S$. pombe, we generated a barcode-tagged $S$. pombe library of random insertion mutants that retains features equivalent to the budding and fission yeast ORF deletion mutant collections, enables identification of mutants in the absence of knowing the barcode sequences, and allows parallel analysis with basic molecular biology techniques. We created an insertion DNA cassette composed of the 
ura $^{+}$selectable marker, a random barcode, a "buffer" sequence to protect the barcode from degradation during integration, and other sequences to allow modifications of the integrated vector. Of the $\sim 10,000$ insertion mutations generated, phenotypic analysis and mapping of a subset indicated that the insertions were broadly distributed in the genome. Thus, this work demonstrates the feasibility and potential utility of constructing barcoded, random insertion libraries in $S$. pombe, and provides approaches that can allow rapid analysis of large collections of barcode-tagged mutations in other organisms.

\section{Results}

A linear DNA vector loses sequences from the ends during non-homologous recombination-mediated insertion in S. pombe

As a first test of using insertion mutagenesis to generate barcode-tagged insertion mutations in S. pombe, an initial barcoded insertion vector was made by PCR amplification of the $\mathrm{ura}^{+}$gene using $u r a 4^{+}$-specific primers to produce a $u r a 4^{+}$gene with a random barcode sequence at its 3 ' end (Figure 1A). Cells with the ura4-D18 mutation were transformed with the linear vector DNA and maintained on minimum medium without uracil to select for $\mathrm{Ura}^{+}$transformants. Anticipating that the majority of the transformants would carry extrachromosomal $\mathrm{ura}^{+}$circles, the initial transformants were re-grown twice on non-selective medium to allow cells to lose unstable $u r a 4^{+}$circles. These colonies were then replica-plated onto both selective medium and minimum medium plates with 5-fluoroorotic acid (5-FOA, $1 \mathrm{~g} / \mathrm{l}$ ) to identify transformants with stably integrated $\mathrm{ura}^{+}$, which are inviable in 5-FOA medium $[27,28]$.

The initial test with $199 \mathrm{Ura}^{+}$transformants identified eight that were sensitive to 5-FOA, indicating that only about $4 \%$ of the transformed cells contained stably integrated DNA. The rest of the transformants (96\%) likely carried the $\mathrm{ura}^{+}$marker extrachromosomally and had lost the circular ura $^{+}$DNA upon growth on 5-FOA-containing medium. Analysis of the eight $\mathrm{ura}^{+}$insertion mutants by PCR revealed that seven mutants had lost their barcodes, indicating that successful integration was frequently accompanied by deletion of barcodes. These results are consistent with previous observations of low frequency stable integration by non-homologous recombination and deletion on the ends of the inserted DNA [20,21,25], underscoring the need to increase the proportion of stable transformants and to prevent deletion of barcodes.

\section{Construction and characterization of the bacterial barcode-tagged insertion DNA library}

The final insertion DNA vector contains a barcode between a "buffer sequence" and the 5 ' end of the $\mathrm{ura}^{+}$ gene so deletions would first occur in the buffer sequence

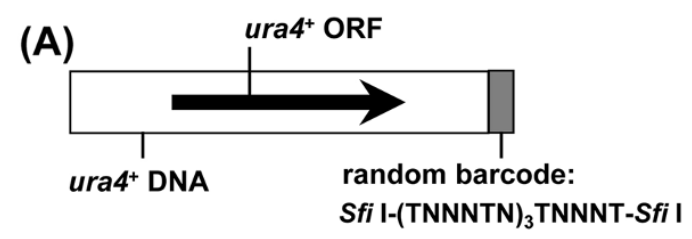

(B)

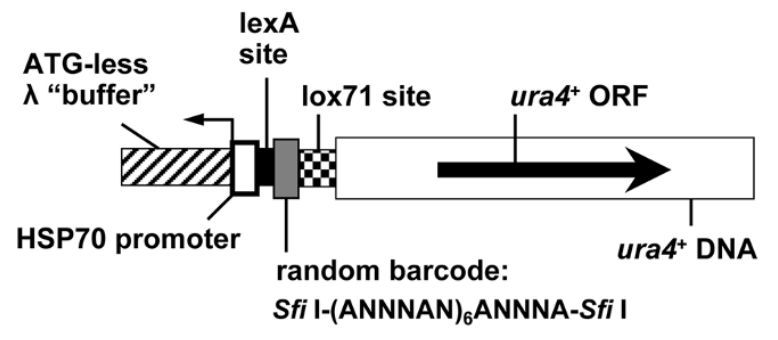

Figure $1 \mathrm{~A}$ non-homologous recombination-mediated insertion mutagenesis for generating an S. pombe mutant library. (A) The first insertion vector tested had the selectable marker $\mathrm{ura4}^{+}$and a 15-bp random barcode directly following the $3^{\prime}$ UTR of $\mathrm{ura}^{+}$. (B) The insertion vector used to construct the $S$. pombe insertion mutant library is composed of a selectable marker ura $^{+}$gene, a barcode (27 random nucleotides with 14 interspersed A's), a lox71 site for oneway integration of lox66-bearing DNA, a mutated human HSP70 promoter with a lexA binding site and a modified $\lambda$ phage sequence, ATG-less $\lambda$, to protect the sequences $3^{\prime}$ to the $\lambda$ phage fragment from degradation.

or the selectable marker before altering the barcode (Figure 1B and Table 1). This buffer sequence included new sequence elements with additional potential functions: a modified 250 bp $\lambda$ DNA sequence (ATG-less $\lambda$ ) at the 5' end to prevent the degradation of the barcode, followed by a modified human HSP70 promoter that contains a lexA binding site $[29,30]$, and a mutated loxP site named lox71 [31]. The lexA-HSP70 promoter can be bound by any lexA fusion protein and may stimulate transcription through the $\lambda$ DNA sequences, which have been modified to contain no ATG sequences, and would translate the first ATG in $S$. pombe genomic DNA [32]. The lox71 site can, in the presence of Cre recombinase, recombine with the lox66 site to allow integration (but not excision) of a plasmid [31].

The new barcode consists of a 27-nucleotide random sequence that is interrupted at specific positions with $14 \mathrm{~A}$ bases. This "interrupted barcode" is flanked by two Sfi I restriction sites so that the barcodes can amplified by PCR, digested with $S f i$ I restriction endonuclease and oligomerized in a head-to-tail orientation for sequencing several barcodes in a single reaction (Figure 2A). As a test of this approach, a fragment containing the barcode DNA and flanking insertion vector sequences was first PCR amplified and then digested with $S f i$ I. Gel-purified barcode monomers were then ligated together to form oligomers 
Table 1 Summary of individual components of the insertion vector

\begin{tabular}{ll}
\hline DNA sequence & Function \\
\hline ATG-less $\lambda$ buffer & $\begin{array}{l}\text { Protect the lexA-HSP70 promoter and } \\
\text { the barcode from degradation } \\
\text { HSP70 promoter }\end{array}$ \\
$\begin{array}{l}\text { Drive the expression of adjacent genes } \\
\text { The binding site for LexA-VP16 protein for } \\
\text { inducible activation of the HSP70 promoter } \\
\text { Random barcode }\end{array}$ & $\begin{array}{l}\text { A specific DNA tag in each mutant for } \\
\text { tracking mutant frequency }\end{array}$ \\
ura4 & The selectable marker
\end{tabular}

(Figure 2B, details in Materials and Methods). A ladder of barcode oligomers was generated, and cloning and sequencing of those oligomers longer than five barcodes confirmed that they were ligated in a head-to-tail manner. We have successfully cloned and sequenced up to 16 tandem barcodes per plasmid, and could routinely clone an average of seven barcodes per plasmid in pilot experiments (data not shown). Thus, when sampling a population of random mutants, each sequenced plasmid provides information on about seven different barcodes and sequencing 20 to 30 plasmids can provide a sufficiently large sample size to identify barcodes that are present at high frequency.

As the barcodes used in this work were designed with 27 random bases, they provide a total of $4^{27}$ or $1.8 \times 10^{16}$ possible barcode sequences. We generated a barcode library of $6.99 \times 10^{6}$ bacterial clones from 37 sub-libraries containing $8.5 \times 10^{4}$ to $2.6 \times 10^{5}$ clones per sub-library. Each sub-library contains independent and different random barcodes and helps preserve the high complexity of the library. Our goal was to generate 10,000 fission yeast mutants with unique and non-redundant barcodes, which should give a $76 \%$ chance to cover all annotated genes (details in Materials and Methods). In general, the number of fission yeast mutants produced was $\leq 1 \%$ of the total number of barcode clones present in the bacterial sublibraries used for mutagenesis, so all mutants have a $\geq 95 \%$ chance of having unique barcodes.

\section{Construction of the fission yeast barcode-tagged insertion mutant library}

The $2.1 \mathrm{~kb}$ linear barcoded insertion vector DNA was purified from the bacterial barcode sub-libraries after digestion with $B a m H$ I enzyme and used to generate the initial transformants. To enrich the overall proportion of stable integrants, we tested the possibility of utilizing low concentrations of 5-FOA to select against cells bearing multiple copies of extrachromosomal $\mathrm{ura}^{+}$circles. Cells bearing $\mathrm{ura}^{+}$circles are expected to have multiple $\mathrm{ura}^{+}$ genes per cell. Higher levels of Ura4 protein should produce more toxic 5-fluorouracil in the presence of low

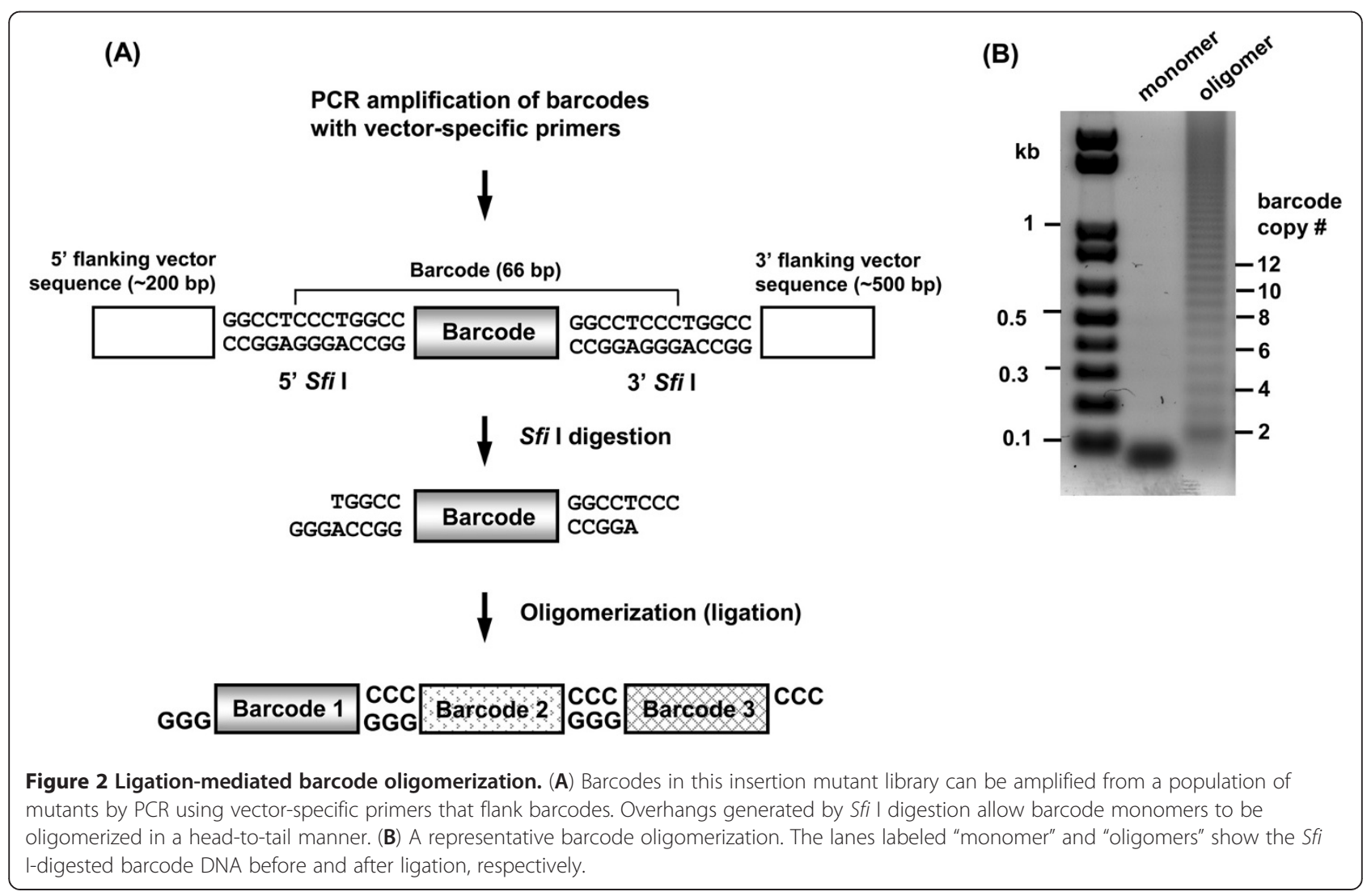


concentrations of 5-FOA, causing these cells to have a growth disadvantage (Additional file 1, Figure S1A). In contrast, stable integrants with one or few copies of integrated $\mathrm{ura}^{+}$DNA do not produce as much Ura4 protein, and are less sensitive to the same treatment (Additional file 1, Figure S1B). To test this assumption, fission yeast cells transformed with the linear insertion vector DNA were immediately plated on low-dose 5-FOA selective medium plates $(100 \mathrm{mg} / \mathrm{l}$ of 5 -FOA, the highest concentration in which the cells with a single copy of $\mathrm{ura}^{+}$gene can survive; unpublished observation). The resulting transformants were verified for stable integration by growing them on normal-dose 5 -FOA medium (1 g/l of 5-FOA) and minimum medium plates without uracil. An initial test on 100 transformants grown on low-dose 5-FOA medium plates identified 30 transformants which died when transferred to medium with normal-dose 5-FOA plates. This result indicates $30 \%$ of the transformants contained stably inserted vector DNA, a significant enrichment of mutants with stable integration compared to the previously observed $4 \%$.

The low-dose 5-FOA selection procedure was used in large-scale generation of fission yeast insertion mutants (Figure 3). Transformants obtained on low-dose 5-FOA selective medium plates and passing the first verification on normal-dose 5-FOA medium plates were transferred to non-selective medium in 96-well plates. Each four 96-well plates were then used to make one 384-colony array on a selective medium and a normal-dose 5-FOA Omni plate to confirm the $\mathrm{Ura}^{+}$and 5-FOA-sensitive phenotypes of stable insertion mutants. Mutants behaving as true stable insertion mutants were stored individually in 384-well plates (28 plates in total). In addition, five $~ 1,800$-mutant pools (each from five 384-well plates) and one $\sim 1100 \mathrm{mu}-$ tant pool (from three 384-well plates) were made for a total of $\sim 10,000$ mutants.

\section{The insertion mutant library contains diverse mutations}

To evaluate the diversity of mutations in the insertion mutant library, four genetic screens were performed on 3600 mutants from ten 384-well plates for phenotypes that could be easily scored.

In the first screen, we looked for mutants that grew slowly or could not grow on minimum medium plates supplemented with only adenine, leucine and histidine to complement the original auxotrophic mutations in our strain. We discovered 30 mutants containing mutations that impeded growth enough to prevent visible colony formation on minimal medium. Based on the Gene Ontology database (GO)-predicted mutant frequency [33] and the fact that only $\sim 57 \%$ of the $S$. pombe genome contains protein coding genes in which mutations are more likely to generate detectable phenotypes than in intergenic regions [10], 37 auxotrophic mutants would be expected in the 3600 insertion mutants assayed
(Table 2). Because not every mutation will generate a visible phenotype, the frequency of auxotrophic mutants in this assay was consistent with the GO prediction.

In the second assay, we selected for mutations that altered colony color on low adenine medium. As the parental yeast strain of the insertion library mutants contains the ade6-M216 mutation, we screened for an alteration in colony color from pale pink (the ade6-M216 phenotype) to red or white when cells were grown in rich medium with low concentrations of adenine. Mutations in only two genes, ade $^{+}$and $a d e 7^{+}$, are known to cause red pigment accumulation in cells. One mutant out of the 3600 screened showed dark red colony color on low adenine medium plate and was identified as an ade 7 insertion mutant (Table 2 and mutant 13_C10 in Additional file 2: Table S1). Thirteen mutants which turned white on low adenine medium plates were also isolated. Although this phenotype can be associated with mutations in the adenine biosynthesis pathway that produce substrates for the Ade6 and Ade7 enzymes, mutants with compromised mitochondrial function have also been reported to demonstrate a similar phenotype $[34,35]$.

In the third test, we screened for temperature-sensitive mutations that allow mutant cells to grow normally at $30^{\circ} \mathrm{C}$, but not at $36^{\circ} \mathrm{C}$. A total of 25 such mutants that grew slowly or could not form visible colonies at $36^{\circ} \mathrm{C}$ were recovered (Table 2). Mutations that cause temperature-sensitive growth are not well-characterized, so these data cannot be used to estimate the expected mutant frequency. However, the isolation of temperature-sensitive mutants does demonstrate the wide variety of mutations present in the library.

In the fourth experiment, we selected for mutations that confer cellular resistance to ethidium bromide (EtBr). EtBr toxicity is primarily due to inhibition of the circular mitochondrial genome. As with mammalian cells, S. pombe requires a functional mitochondrial genome for survival so $\mathrm{EtBr}$ is highly toxic. If $S$. pombe and mammalian cells acquire certain nuclear mutations, the so-called $r h o^{0}$ cells devoid of mitochondrial DNA can be generated by long term selection in EtBr-containing medium with specific supplements [12,37]. Using this EtBr selection procedure, we identified 13 strains that are EtBr-resistant (Table 2).

To determine whether these mutant phenotypes were caused by the $\mathrm{rat}^{+}$insertion or mutations induced by transformation, we crossed the mutants to a wild type strain and performed tetrad analysis on a subset of the identified mutants to verify co-segregation of the $u r a 4^{+}$ marker and the phenotypes. Of 34 strains examined, 28 showed 2:2 segregation of $\mathrm{ura}^{+}$in (on average) seven tetrads (Additional file 2: Table S1). By this criteria, the majority of mutants contained single insertions. Of the 18 mutants that showed slow or no growth on minimum medium, the $\mathrm{rra}^{+}$marker co-segregated with the phenotype in a 2:2 ratio in 16 mutants, indicating that most of the 


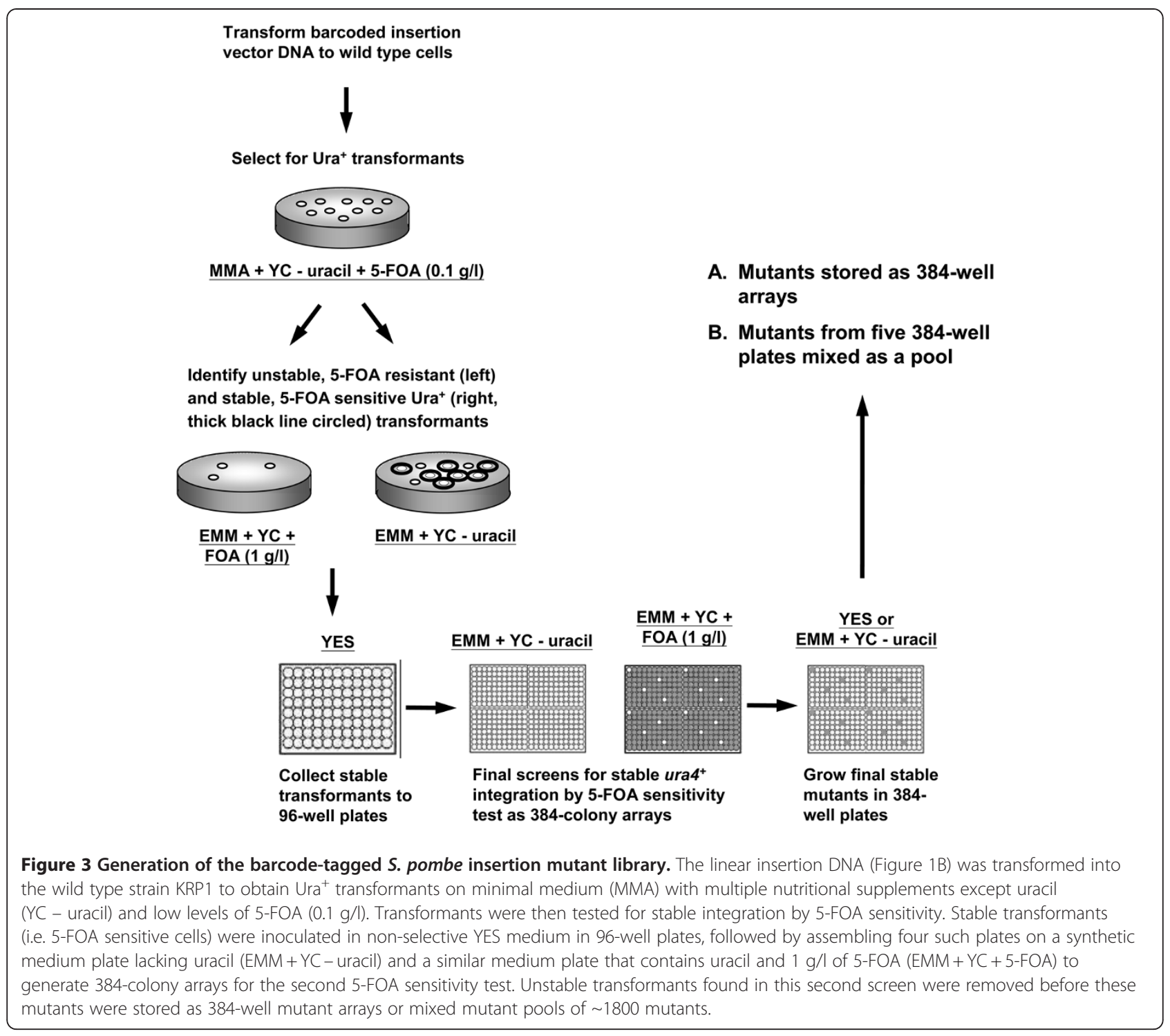

mutant phenotypes were linked to the insertion mutations. Similar results were observed in mutants exhibiting altered color on low adenine medium (six out of 10 mutants show complete co-segregation of phenotypes and markers, Additional file 2: Table S1). Of the 11 temperature-sensitive mutant assayed, one was sterile, four showed poor spore viability and three of the remaining six showed 2:2 cosegregation with $\mathrm{ura}^{+}$(Additional file 2: Table S1 and data not shown). The source of the unlinked mutations is unknown but may be due to the mutagenic effects of transformation [38,39], and underscores the requirement of validating mutants from premade collections by recreating the mutation in a new strain to determine if the phenotype is regenerated. The sum of these data show that the majority of these insertions contain the $u r a 4^{+}$vector in a single locus and the insertion locus is genetically linked to the mutation in most of these mutants.
Mapping of insertion sites and analysis of the structures of inserted vectors

Previous studies on non-homologous recombinationmediated mutagenesis in $S$. pombe showed that the genomic locations of insertion vectors were difficult to determine by inverse PCR [21]. We therefore tested two previously established methods for large-scale insertion site determination, thermal asymmetric interlaced (TAIL)-PCR [40,41] and splinkerette-adaptor PCR [42,43]. TAIL-PCR uses alternating high and low annealing temperatures, a set of arbitrary degenerate $(\mathrm{AD})$ primers and three nested insertion DNAspecific primers to amplify a small region of insertion DNA and the adjacent genomic sequence (Additional file 3: Figure S2A) [40,41]. TAIL-PCR only detected genome-insertion junctions in a portion of mutants analyzed (described below). In some mutants, only repetitive insertion vector sequences were amplified, indicative of tandem 
Table 2 Assessment of mutation diversity in the barcode-tagged insertion mutant library by four genetic screens

\begin{tabular}{|c|c|c|c|c|}
\hline Mutation & Phenotype & $\begin{array}{l}\text { AmiGO or } \\
\text { KEGG expectation }\end{array}$ & $\begin{array}{l}\text { Expected number } \\
\text { in } 3581 \text { mutants }\end{array}$ & $\begin{array}{l}\text { Actual number } \\
\text { of isolates }\end{array}$ \\
\hline Auxotrophy & $\begin{array}{l}\text { Slow or no growth on } \\
\text { minimal medium }\end{array}$ & $2.4 \%\left(94^{\mathrm{a}} / 5122^{\mathrm{b}}\right)$ & $37^{c}$ & 30 \\
\hline \multirow{2}{*}{$\begin{array}{l}\text { Defective adenine } \\
\text { biosynthesis }\end{array}$} & \multirow{2}{*}{$\begin{array}{l}\text { Colony color change from } \\
\text { pale pink to white or red on } \\
\text { low adenine medium }\end{array}$} & $N D^{d}$ & $N D^{d}$ & 13 (white ${ }^{d}$ ) \\
\hline & & $0.04 \%\left(2^{e} / 5122^{b}\right)$ & $1-2^{e}$ & 1 (red) \\
\hline Temperature sensitivity & Slow or no growth at $36^{\circ} \mathrm{C}$ & $N D^{f}$ & $N D^{f}$ & 25 \\
\hline $\begin{array}{l}\text { EtBr resistance } \\
\text { (petite positivity) }\end{array}$ & Growth in medium with $\mathrm{EtBr}$ & $N D^{f}$ & $N D^{f}$ & 13 \\
\hline
\end{tabular}

a. The estimated number is from AmiGO database [33] by searching genes using keywords "amino acid biosynthesis" and "nucleobase biosynthesis", and excluding genes involved in the adenine, histidine, leucine and uracil pathways as the parental strain in defective in these pathways and all mutants are Ura ${ }^{+}$.

b. Total gene number in S. pombe genome (as of $2 / 27 / 2012$ ) $=5122$.

c. The estimated number is calculated as "the total number of mutants tested (3581)" $\times$ "AmiGO expectation" $\times$ "the fraction of protein coding sequences in the total S. pombe genome (57\%)".

d. Not determinable; white colony color could also result from mitochondrial defects [34,35].

e. The estimated number is from KEGG [36] $\left(a d e 6^{+}\right.$and $\left.a d e 7^{+}\right)$.

f. Not determinable; no associated terms or categories in AmiGO or KEGG.

integration of vector DNA in these mutants (data not shown). In other mutants, mitochondrial DNA was found co-integrated with insertion vector (data not show). These results indicate that these additional DNA fragments provided binding sequences for the degenerate or vector- specific primers (Additional file 3: Figure S2B, C). Therefore, we also used splinkerette PCR, which involves ligating a double strand DNA adaptor to genomic DNA fragments digested with restriction enzymes that cut frequently in the genome but not in the vector (e.g. Spe I and Xba I, Additional file 4: Figure S3) [44]. The resulting products provide templates for PCR amplification of neighboring genomic DNA using specific primers on the splinkerette adaptor and insertion vector. The splinkerette approach produced PCR fragments of defined size and some genomic sequences, allowing the estimation of the region of the insertion in some mutants and detection of insertion-chromosome junction in others (Additional file 2: Table S1). As the splinkerette approach also gave vector or mitochondrial sequences in some mutants, we pursued additional mapping approaches.

We adapted splinkerette and inverse PCR to a new method, inverse splinkerette PCR, which may eliminate extra copies of tandem insertion vector in some mutants before PCR (Figure 4). In inverse splinkerette PCR, genomic DNA from insertion mutants was digested with a restriction enzyme that cuts once (or very few times) in the insertion vector and frequently in the genome (e.g. EcoR V in this work). The digestion generates fragments with one chromosomal DNA end and one insertion vector end, which can be brought together by intramolecular ligation to produce circular DNA. Digestion of the ligated DNA with $S f i$ I enzyme linearizes circular DNA composed of truncated 5' part of the insertion vector and a genomic fragment, and generates a unique overhang on the $\lambda$ buffer of vector for ligating splinkerette adaptor. The genomic DNA bordered by the partial vector DNA and splinkerette adaptor can be amplified by specific primers on insertion vector and splinkerette. This method can reveal the EcoR V site closest to the insertion site and together with the length of the PCR product, to generate an approximate location of the insertion mutation (Additional file 2: Table S1). In cases where the EcoR V site is very close to the insertion site, one may detect the precise junction sequences between chromosomes and insertion vector.

We also directly cloned the genomic sequences flanking the insertion vector in $E$. coli by the lox66/lox71 integration system (Figure $5 \mathrm{~A}$ ). As the insertion mutations are all marked with the mutated loxP sequence, lox71, introducing a plasmid bearing the lox66 sequence into cells expressing Cre recombinase should allow stable integration of the lox66 plasmid into the lox71 sequence. We therefore transformed the plasmid pLox66, which has the lox66 sequence and a selectable marker for G418 resistance in yeast and kanamycin resistance in E. coli, into S. pombe insertion mutant cells bearing the pREP81 plasmid with or without the Cre recombinase gene. Because pLox66 does not contain a functional yeast replication origin, integration into the genome is required for its stable inheritance and G418 resistance in yeast cells. Following introduction of pLox66, cells expressing Cre recombinase produced more G418- resistant colonies than cells without $\mathrm{Cre}$, indicating that Cre promotes efficient integration of pLox66 into the genome (Figure 5B). Specific integration of pLox66 to lox71 of the insertion vector was verified by $\mathrm{PCR}$ using primers on pLox66 (B, C, Figure 5A) and the insertion vector (A, D, Figure $5 \mathrm{~A}$ ). While expected PCR products were generated from Cre-expressing cells, the same PCR reactions using those G418-resistant cells without Cre did not yield bands corresponding to pLox66 integration, indicating these cells 


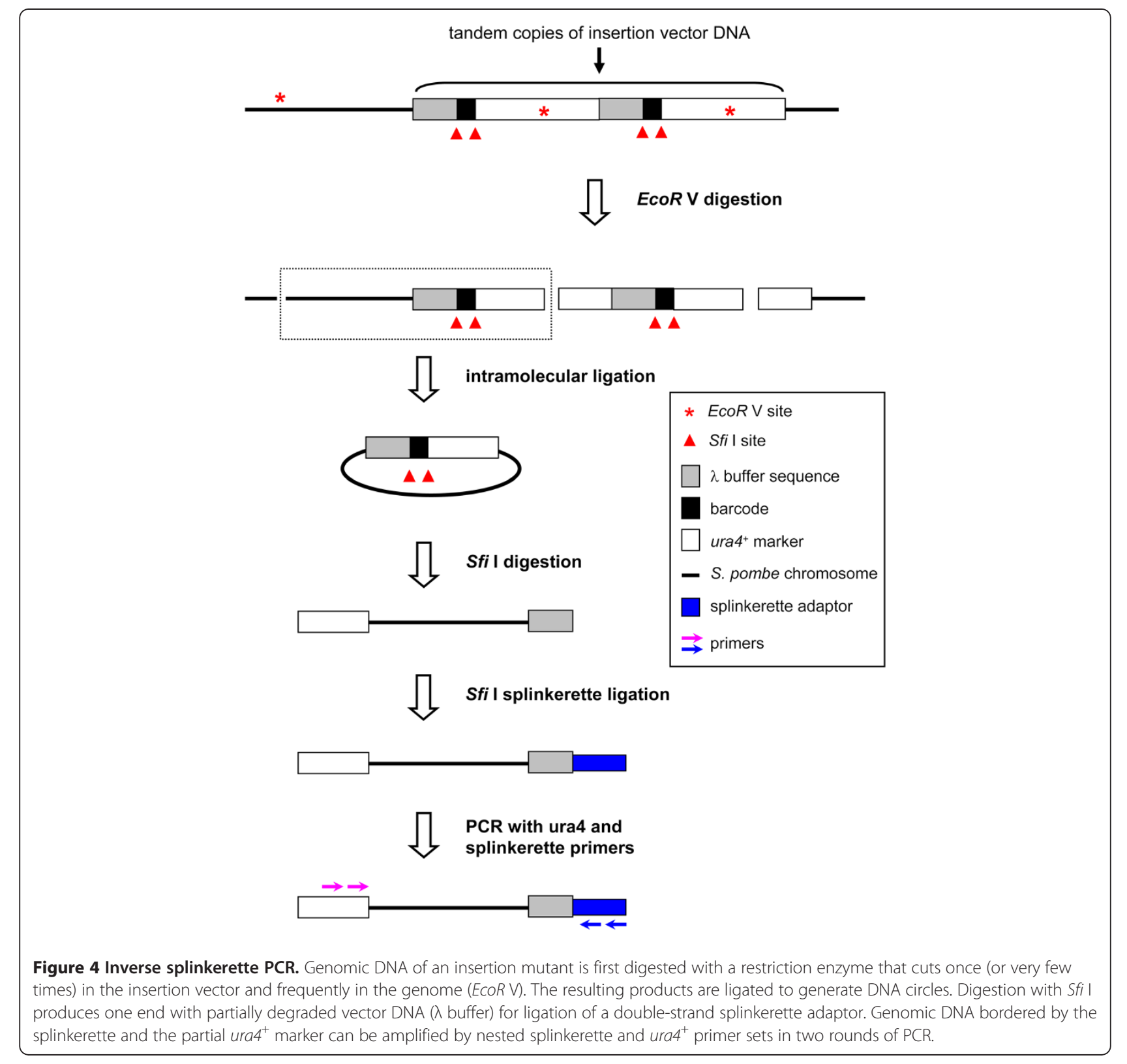

may bear pLox66 extrachromosomally (Figure 5C). Sequencing of PCR products from cells expressing Cre also confirmed that they contained the recombined lox66/lox71 hybrid and the wild type loxP sequences (Figure 5D).

To clone genomic DNA flanking the insertion sites, genomic DNA of G418-resistant, pLox66-integrated cells was digested with Spe I and Xba I, and ligated under conditions favoring intramolecular ligation. The presence of the pUC origin on pLox66 allowed us to clone genomic sequences neighboring the insertion site in E. coli for sequencing (Figure 5A). Using this method, we cloned and verified the insertion site of the mutant 18_M24 (Additional file 2: Table S1).
Using TAIL-PCR, we initially characterized 44 mutants, of which we were able to determine the genomic sequences at one end of the insertion sites in 24 mutants. In 12 mutants, only repetitive insertion vector sequences were amplified and sequenced, and mitochondrial DNA was found co-integrated with insertion vector in eight mutants (Additional file 2: Table S1 and data not shown). We have also used inverse splinkerette PCR to map insertions in 38 mutants and determined approximate location of the insertion vector in 14 mutants, nine of which we were not able to determine by TAIL-PCR (Additional file 2: Table S1). These results suggest that although TAILPCR and inverse splinkerette PCR are not sufficient for 
(A)
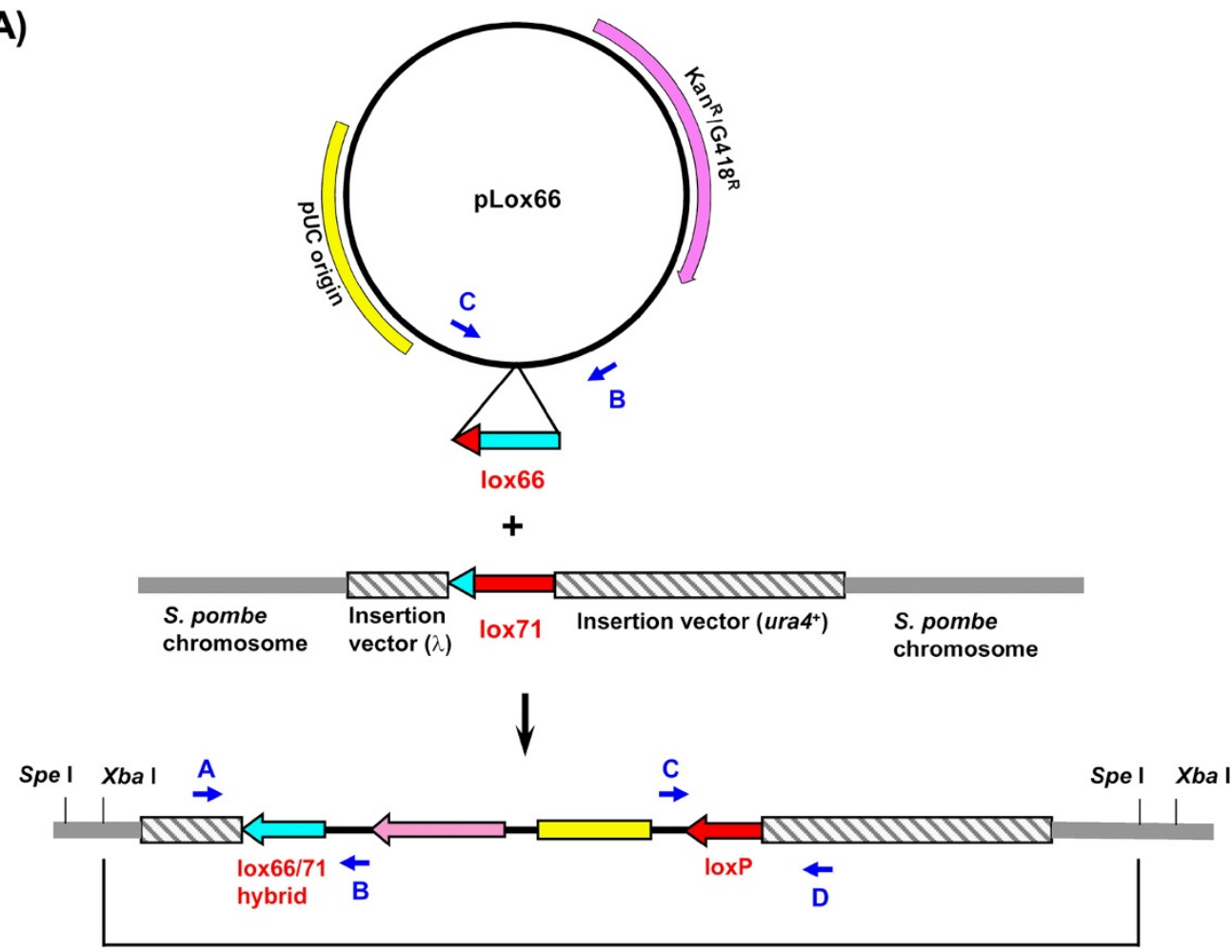

Restriction enzyme digestion, circularization and cloning in E. coli

(B)

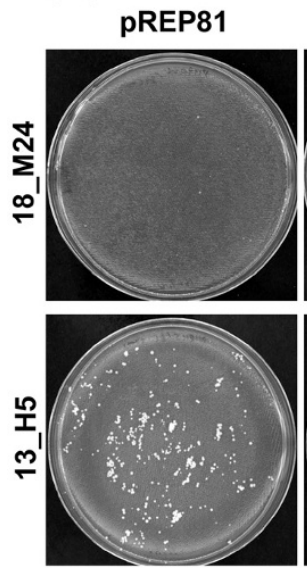

(C)
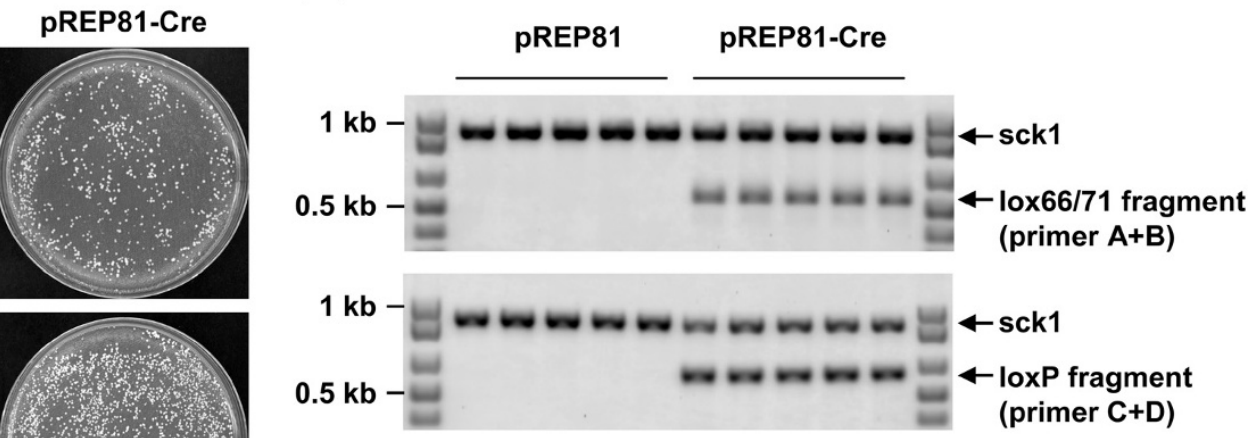

(D) loxP: ATAACTTCGTATAGCATACATTATACGAAGTTAT

10x71: TACCGTTCGTATAGCATACATTATACGAAGTTAT

10x66: ATAACTTCGTATAGCATACATTATACGAACGGTA

10x66/71: TACCGTTCGTATAGCATACATTATACGAACGGTA

Recombined loxP site in 18_M24

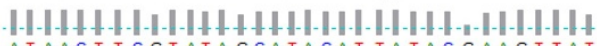
ATAACT T C G TATAGCATACAT TATACGAAGTTAT 120 100

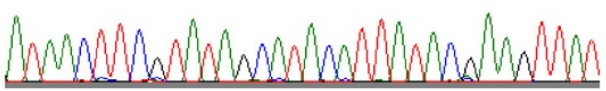

Recombined lox66/71 site in 18_M24

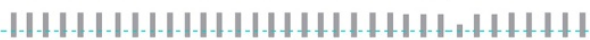
TACCGTTCGTATAGCATACATTATACGAACGGTA

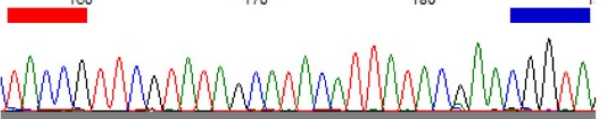

Figure 5 (See legend on next page.) 


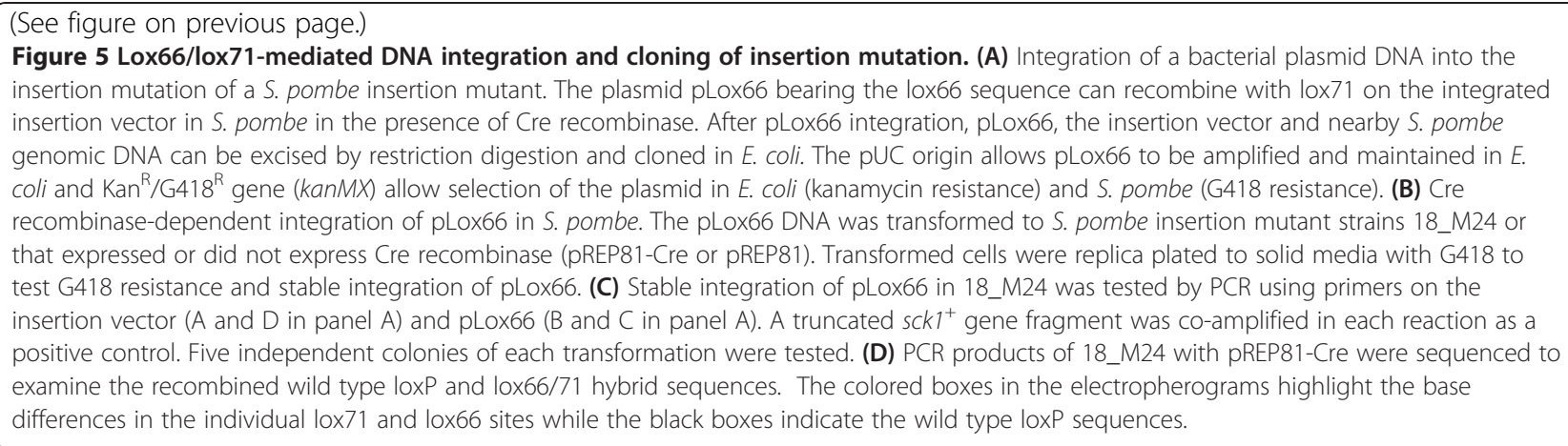

mapping all insertion sites, they are complimentary to each other in deciphering insertion positions accompanied by different insertion structures. Splinkerette PCR and lox66/ 71-based cloning also allowed the determination of insertion sites (Additional file 2: Table S1).

Among the 38 mutants in which exact or approximate insertion locations were determined, 13 of them have insertion mutation on chromosome 1 , with 16 on chromosome 2 and 9 on chromosome 3. In the 27 mutants where at least one end was mapped to a defined locus, 16 were located in ORFs or non-coding RNA genes and 11 were found in intergenic regions.

In the seven mutants in which both ends of the insertion sites were characterized, deletions of genomic sequences ( $\leq 5 \mathrm{bp}$ ) were found in only three mutants (13_H5, 18_M24 and 1a7-4033, Additional file 5: Table S2), and deletions of a wide range of sizes, from $5 \mathrm{bp}$ to $1.8 \mathrm{~kb}$, were observed at ends of the insertion vectors in all mutants. Tandem integration of multiple insertion vectors were detected in all but one mutant (1a-4032) in head-to-tail, head-to-head or tail-to-tail orientations. The structures of the insertion vectors in these mutants is consistent with the ends of some linear vector DNA being resected by nucleolytic activities in cells and ligated together before being integrated as tandem copies into the genome as previously observed by others (Additional file 5: Table S2 and Additional file 6: Figure S4, and $[20,21,25])$.

\section{Discussion}

In this study, we created a fission yeast insertion mutant library in which all mutants were tagged with unique barcode sequences and stored as two readily available selection platforms. The 384-well mutant arrays allow genetic screens on individual mutants and can be extended to genetic approaches such as synthetic genetic array (SGA) $[45,46]$. These mutant arrays have been used to identify mutants with four distinct phenotypes (Table 2) as well as strains that are hyper-sensitive to cancer chemotherapeutics camptothecin and bleomycin (Hale and Runge, unpublished data). In addition to 384-well mutant arrays, mutant pools of 1800 mutants are available for parallel analysis.

The insertion mutagenesis used in this study relied on random non-homologous recombination, where a vast majority of transformants have unstable, circularized vector DNA and only a small portion have stable insertions. To facilitate the collection of stable insertion mutants, we included low-dose 5-FOA in our initial selecting medium as an effort to eliminate unstable cells bearing high copy number of $\mathrm{ura}^{+}$vector and producing high levels of Ura4p (Additional file 1: Figure S1), and subsequently rescreened for mutants that were stably $\mathrm{ura}^{+}$and 5-FOAsensitive (Figure 3). While this approach increased the proportion of stable insertion mutants among the total transformants (from $4 \%$ to $30 \%$ ), we note that some mutants might have been excluded. For example, insertions into genomic regions where expression switches between on and off states (e.g. telomeres [47]) would be excluded from the final library. Likewise, insertion at a locus that causes high $\mathrm{ura}^{+}$expression or tandem integration of many functional $\mathrm{ura}^{+}$markers could result in increased sensitivity to low-dose 5-FOA and eliminate some mutants during the initial selection.

To increase the versatility of the mutant library, some previously characterized functional DNA sequences were included in our insertion vector, including the lox71 sequence and the mutated human HSP70 promoter. We demonstrated that the mutated lox66 and lox71 could undergo Cre recombinase-dependent integration in $S$. pombe, similar to what has been reported in mammalian cells [29], and showed that this method can be used to clone genomic sequences surrounding the insertion mutations using the pLox66 plasmid. The mutated human HSP70 promoter, which exhibits dramatically reduced activity in $S$. pombe, was tethered with a lexA binding site for its potential activation by a lexA DNAbinding domain and transactivator fusion protein. While the goal was to provide an opportunity to ectopically express nearby genes, the tandem integrations of insertion vector and co-integration of mitochondrial DNA could impede the utilization of this promoter to activate genes 
near the insertion site. Testing of the HSP70 promoter was, therefore, not pursued.

Another novel addition to this insertion mutant library is the inclusion of unique barcodes. These barcodes allow one to take a census of the selected mutants by tracking barcode frequencies after the selection. Barcode sequencing can be facilitated by converting individual Sfi I site-bordered barcodes to barcode oligomers (Figure 2), which allows for the generation of multiple barcode sequences per Sanger sequencing reaction, providing a cost-effective and rapid alternative compared to cloning and sequencing individual barcodes. Although the high-throughput sequencing or microarray is possible analytic means for our mutant library, the design of our barcodes provides a medium-throughput alternative which requires only easily accessible laboratory techniques. Moreover, in contrast to the necessity of sophisticated bioinformatics support for microarray and high-throughput sequencing, the sequences of several hundred barcodes obtained from our approach can be easily sorted and analyzed with basic spreadsheet software. We note that our oligomerization and sequencing strategy can also be used to monitor other nucleic acids in cells (e.g. RNAs, mitochondrial genomes). By amplifying a small region around a sequence difference between two different nucleic acids, our oligomerization and sequencing method can easily produce $\sim 200$ or more sequences, which should be sufficient for determining the relative proportions of the two forms with data that are much easier to process than data from a high-throughput sequencing experiment.

Random insertion mutant libraries may overcome some challenges in the study of essential genes. Mutants that lack essential genes are not present in haploid gene deletion mutant banks such as the budding and fission yeast ORF deletion collections. Among the $S$. pombe insertion mutants analyzed in this work, we found that in six mutants, the insertions were identified in or adjacent to essential genes (Additional file 2: Table S1), presumably generating truncated proteins or altering the expression of these genes. These results indicate that this insertion mutant library approach provides opportunities for functional analysis of essential genes.

The insertion events characterized in this library are consistent with those shown in previous studies, including insertions in both genes and intergenic regions, large deletions of insertion DNA and little or no deletions of surrounding chromosomal sequences (Additional file 5: Table S2, and [20,21,25]). We also discovered 16 mutants with mitochondrial DNA cointegrated with the insertion vector. The presence of mitochondrial DNA in the wild type $S$. pombe nuclear genome has recently been characterized with one wild type strain containing 12 mitochondrial DNA insertions in its nuclear chromosomes [48]. Mitochondrial DNA fragments were also found in all repaired plasmid-based double strand breaks in $S$. pombe cells in an independent study [26]. It is worth noting that capture of mitochondrial DNA in the nuclear genome has also been observed in hemiascomycetous yeasts, plant, insect, rodent and human cells and appears to be an active and ongoing process [49-55], indicating that $S$. pombe transformation provides a way to study this process.

One consequence of mitochondrial and tandem $\mathrm{ura4}^{+}$ DNA insertions is that they can impede the detection of the insertion sites by TAIL-PCR. We have tested three additional approaches for mapping insertion mutations: splinkerette PCR, inverse splinkerette PCR and lox66/ 71-dependent cloning. While these methods were not $100 \%$ efficient, we showed that they could complement each other in defining insertion sites. One advantage of TAIL-PCR is that it detects the junction of insertion vector and genomic sequences and provides the exact location of the integrated vector. In contrast to TAIL-PCR, inverse splinkerette PCR in our mutants directly determined the closest EcoR V sites to the 5' end ( $\lambda$ buffer end) of insertion vector. Together with the length of the PCR products, only approximate regions of insertion could be obtained. While we did not follow up results from our inverse splinkerette PCR, one could determine the exact location of insertion by cloning the PCR product and sequencing the genomic regions with genespecific primers. Depending on the complexity of insertion structure, splinkerette PCR could determine the insertion vector-chromosome junction or the closest restriction sites used in the assay to the insertion site. It is important to note that all mutants are tagged by the lox71 sequence, which allows the cloning of the genomic sequences flanking the insertion in E. coli in the event that insertion mutations could not be mapped by these three PCR methods.

In addition to non-homologous recombination-based integration, other methods for generating insertion mutations include transposon-mediated mutagenesis. At least three types of transposons have been analyzed in a genome-wide context in S. pombe. The S. pombe retrotransposon Tf1 has been shown to exhibit preference for targeting the promoters of RNA polymerase II transcribed genes [56]. The piggyBac $(P B)$ transposon, originally isolated from cabbage looper moth, preferably targets TTAA sites in the genome. Although as much as $79 \%$ of transposition events of piggyBac $(P B)$ analyzed in a haploid $S$. pombe strain was located in intergenic regions, it was assumed that this seemingly preference of 
$P B$ transposon for intergenic sequences was a consequence of selective pressure on insertions in ORFs that cause reduced fitness [57]. High throughput sequencing performed in both studies indicated that the transposition events of both transposons broadly distribute among the three chromosomes. The Hermes transposon from housefly Musca domestica has strong preference for $\mathrm{T}$ at position 2 and for $\mathrm{A}$ at position 7 of the target sites and has been adapted for $S$. pombe. The limited number of insertion mutants analyzed in that study suggested that Hermes targets both intergenic regions and coding sequences with no apparent bias [58]. Insertions generated by non-homologous recombination in our work also have a broad distribution on the three chromosomes, similar to what was observed in Tf1 retrotransposon and $P B$ transposon [56,57] and a previous report on non-homologous recombination in $S$. pombe [20]. Although $60 \%(16 / 26)$ of the partially characterized insertions resided in ORFs or non-coding RNA genes, the enrichment of this type of insertions may be due to pre-selection of the corresponding mutants by visible phenotypes. Thus, the three transposon approaches and our insertion vector approach can create a wide variety of mutations. Our approach has the advantage of adding unique barcodes to each insertion, which has not been applied to the transposon approaches.

The main difference between non-homologous integration and transposon transposition is the structures of insertion events. While transposons generally integrate at individual genomic locations as unmodified single copies with defined junctions between genomic and transposon DNA, tandem integration of the insertion vector DNA or co-insertion of non-nuclear DNA during non-homologous recombination-based integration make this junction more variable. The simple insertion events in transposon mutagenesis allow for high-throughput sequencing for mapping insertion sites, while the complex insertion structures generated by non-homologous recombination require insertion sites to be determined by low/medium-throughput approaches. Nonetheless, the high mutation variety, the presence of random barcodes, and the availability of multiple methods for mapping insertion mutations still make this insertion mutant library an attractive tool for genomewide studies that can complement the existing S. pombe ORF deletion set.

\section{Conclusions}

As an effort to further support genome-wide studies in $S$. pombe, we generated a barcode-tagged $S$. pombe insertion mutant library which is available as pools of mixed mutants for parallel analysis and in the form of 384-well mutant arrays for genetic screens on individual mutants. The four genetic screens conducted in this work indicate that the library has a wide variety of mutations and is suited for the selection for diverse phenotypes. The design of the barcode tags allows detection and quantification of the barcodes with readily available molecular biological techniques, and does not require prior knowledge of the barcodes and mutations in the mutant strains to conduct genetic screens. The barcode-tagging strategy described here can be easily adapted to other model systems.

\section{Methods}

\section{Strains and media}

The E. coli electrocompetent cell NEB 5-alpha (Cat\# C2989K, NEB) was used for the construction of the bacterial barcode-tagged insertion DNA library. The auxotrophic fission yeast wild type strain KRP1 [59] (originally designated as CHP429 from C. Hoffman [60]) was used to construct the fission yeast insertion mutant library.

Unless otherwise specified, yeast extract $+225 \mathrm{mg} / \mathrm{l}$ of supplements (YES) contains 3\% glucose, and Edinburgh minimal medium (EMM) contains 2\% glucose [61]. $\mathrm{EMM}+\mathrm{FOA}$ contains $1 \mathrm{~g} / \mathrm{l}$ of 5 -FOA, 2\% glucose, $50.25 \mathrm{mg} / \mathrm{l}$ of uracil [62]. Minimal medium agar (MMA) has $1 \%$ glucose [63]. For EMM, EMM + FOA and MMA media, the yeast complete supplements (YC - uracil) (Additional file 7: Table S3) were also included to allow the growth of additional auxotrophic mutants generated in this work.

\section{Construction of the bacterial barcode-tagged insertion DNA library \\ Construction of the insertion DNA vector}

The protective $\lambda$ buffer DNA and lexA-HSP70 promoter was created by PCR using nine overlapping oligonucleotides, hsplam1-9, and the primer S.pombeLmbdBrcd. Oligonucleotides used in this study are listed in Additional file 8: Table S4. This procedure removed all ATG codons in the transcribed strand of the $\lambda$ buffer sequence. The final product (ATG-less $\lambda$-lexA-HSP70) contains the ATGless $\lambda$ buffer sequence, a mutated human HSP70 promoter, a lexA site and a 3' Blp I site.

The selective marker ura $^{+}$(InvU4) was first generated by PCR with primers InvU4S and InvU4-AS and wild type KRP1 genomic DNA as the template. A double strand lox71 DNA fragment was synthesized by annealing oligonucleotides lox71-InvU4S1 and lox71-InvU4AS1 and subsequent conversion of the annealed DNA to a doublestrand product by Picomaxx (Agilent Technologies) on a thermal cycler by incubating the DNA-enzyme mixture at $94^{\circ} \mathrm{C}$ for $20 \mathrm{~s}$ with a decrease of $0.5^{\circ} \mathrm{C}$ per cycle for 72 cycles until the temperature reached $58^{\circ} \mathrm{C}$. The doublestrand lox71 DNA was used as a mega primer, together with the primer lox71-InvU4AS1, to amplify the InvU4 DNA by initial denaturation for $3 \mathrm{~min}$ at $94^{\circ} \mathrm{C}$, then 
cycling 32 times with $30 \mathrm{~s}$ of denaturation $\left(94^{\circ} \mathrm{C}\right), 30 \mathrm{~s}$ of annealing $\left(48^{\circ} \mathrm{C}\right.$ for the first 16 cycles, $52^{\circ} \mathrm{C}$ for the last 16 cycles) and $1 \mathrm{~min}$ and $45 \mathrm{~s}$ of extension $\left(72^{\circ} \mathrm{C}\right)$, and a final extension step of $7 \mathrm{~min}$ at $72^{\circ} \mathrm{C}$ to generate a final DNA product (lox71-InvU4) that contains a $5^{\prime}$ Sfi I site, a lox71 site and the selectable marker $\mathrm{ura}^{+}$.

The $\lambda$ buffer fragment (ATG-less $\lambda$-lexA-HSP70) and the extended ura $^{+}$marker (lox71-InvU4) were individually cloned to pCR2.1-TOPO vector (Invitrogen) and sequenced. The correct ATG-less $\lambda$-lexA-HSP70 fragment was then purified as a Hind III-EcoR V fragment and ligated to pCR2.1-TOPO-lox71-InvU4 cut with Hind III and Spe I, where the Spe I overhang was rendered blunt by treatment with the Klenow fragment of $E$. coli DNA polymerase I (NEB), to make the final insertion vector construct pCR2.1ATG-less $\lambda$-lexA-HSP70-lox71-InvU4, referred to as "pInsertion-ura4". The complete sequence of pInsertion-ura4 is available as Additional file 9 (pCR2.1-TOPO sequence excluded).

\section{Preparing plnsertion-ura4 vector with a blunt end and a $5^{\prime}$ GGG overhang}

A $0.9 \mathrm{~kb}$ fragment containing part of the $s c k 1^{+}$coding sequence was generated by PCR using primers Stuffer 5 ' Blp I and Stuffer 3' Sfi I and wild type KRP1 genomic DNA as the template (PCR condition: initial denaturation for $3 \mathrm{~min}$ at $94^{\circ} \mathrm{C}$ and cycling 30 times with $20 \mathrm{~s}$ of denaturation $\left(94^{\circ}\right.$ C), $30 \mathrm{~s}$ of annealing $\left(56^{\circ} \mathrm{C}\right.$ for the first 10 cycles, $52^{\circ} \mathrm{C}$ for the last 20 cycles) and $2 \mathrm{~min}$ of extension $\left(72^{\circ} \mathrm{C}\right)$ followed by a final extension step of $5 \mathrm{~min}$ at $72^{\circ} \mathrm{C}$ ). After digesting the PCR product with $B l p$ I and Sfi I, the $s c k 1$ stuffer fragment was inserted at the corresponding sites on pInsertion-ura4. The resulting stuffer plasmid (pInsertion-ura4-sck1) was digested with $B l p \mathrm{I}$, treated with Klenow polymerase and then digested with $S f i$ I. The double-digested vector $(6 \mathrm{~kb})$ was separated from the $s c k 1$ stuffer $(0.9 \mathrm{~kb})$ and partiallydigested vector $(6.9 \mathrm{~kb})$ on a $0.7 \%$ agarose gel and purified.

\section{Insertion of the barcodes and bacterial library preparation}

The double strand barcode inserts were generated from two oligonucleotides, Barcode_3-07B and Barcode_P_3-07. Both oligonucleotides $(20 \mu \mathrm{M})$ were separately heated at $70^{\circ} \mathrm{C}$ for $5 \mathrm{~min}$, chilled quickly on ice and phosphorylated by $\mathrm{T} 4$ polynucleotide kinase (NEB) at $37^{\circ} \mathrm{C}$ for $1 \mathrm{~h}$. The two phospho oligonucleotides were then annealed together by slow cooling on a thermal cycler using the following program: $95^{\circ} \mathrm{C}$ for $1 \mathrm{~min}$ and $30 \mathrm{~s}\left(-1^{\circ} \mathrm{C} /\right.$ cycle, 15 cycles $)$, $80^{\circ} \mathrm{C}$ for $2 \mathrm{~min}\left(-0.5^{\circ} \mathrm{C} /\right.$ cycle, 70 cycles $), 45^{\circ} \mathrm{C} \times 1 \mathrm{~min}$ and $30 \mathrm{~s}\left(-0.5^{\circ} \mathrm{C} /\right.$ cycle, 66 cycles $)$. The annealed oligonucleotides were converted to double strand DNA by the Klenow fragment of E. coli DNA polymerase I (3'-5' exo') (NEB) at $37^{\circ} \mathrm{C}$ for $1 \mathrm{~h}$, followed by $75^{\circ} \mathrm{C}$ incubation for $20 \mathrm{~min}$ to inactivate the enzyme. The resulting double strand barcodes had 5' blunt ends and 3' CCC overhangs that allowed their ligation to pInsertion-ura4 prepared above.

The pInsertion-ura4 vector and barcode DNA insert were ligated together at molar ratios of 1:1 (800 ng: $2.5 \mathrm{ng}$ ) or $1: 3$ (800 $\mathrm{ng}: 7.5 \mathrm{ng}$ ) by T4 DNA ligase (NEB) at $16^{\circ} \mathrm{C}$ for $16 \mathrm{~h}$. Ligated DNA (20 ng or $40 \mathrm{ng}$ ) was transformed to $25 \mu \mathrm{l}$ of $E$. coli electrocompetent cells NEB 5-alpha in a $1 \mathrm{~mm}$ electroporation cuvette on BioRad Gene Pulser II using the setting $1.7 \mathrm{kV}, 200 \Omega$ and $25 \mu \mathrm{F}$. After electroporation, $975 \mu \mathrm{l}$ of SOC was added to the transformed cells, followed by incubation at $37^{\circ} \mathrm{C}$ with $250 \mathrm{rpm}$ shaking for $1 \mathrm{~h}$. To determine the titer of transformation, $3 \mu \mathrm{l}$ of the culture was plated on $\mathrm{LB}+$ ampicillin $(100 \mathrm{mg} / \mathrm{l})$ plates in duplicate. For the remaining cells, aliquots of $100 \mu \mathrm{l}$ were spread on one plate for a total of 10 plates and grown at $37^{\circ} \mathrm{C}$ for overnight. Cells grown on these plates were scraped off and grown in $100 \mathrm{ml}$ of $\mathrm{LB}+$ ampicillin $(100 \mathrm{mg} / \mathrm{l})$ medium at $37^{\circ} \mathrm{C}$ for $4 \mathrm{~h}$ for plasmid DNA and freezer stock preparation.

\section{Construction of the fission yeast barcode-tagged insertion mutant library}

The linear insertion vector DNA was obtained by digesting the pInsertion-ura4-barcode library DNA with $\mathrm{BamH}$ I and gel purifying the $2.1 \mathrm{~kb}$ fragment using QIAGEN Gel Extraction kit, followed by extraction with phenol/ chloroform/isoamyl alcohol (25:24:1; volume: volume: volume) and chloroform/isoamyl alcohol (24:1). For each transformation, $1 \mu \mathrm{g}$ of purified linear barcoded insertion DNA was used to transform $50 \mu \mathrm{l}$ of frozen KRP1 $S$. pombe competent cells (prepared as in [64]). Transformed cells were incubated at $30^{\circ} \mathrm{C}$ in all procedures described below.

Transformed cells were plated on MMA + YC - uracil + 5-FOA (0.1 g/l) (MMA + low FOA), where "YC - uracil" is the complete yeast supplements without uracil to allow recovery of auxotrophic mutants (Additional file 7: Table S3), and grown for at least 5 days. Colonies on MMA + low FOA plates were picked to grid on EMM + $\mathrm{YC}$ - uracil plates, grown for 3 days and replica plated onto YES plates. After growth on YES plates for 2 days, cells were replica plated to $\mathrm{EMM}+\mathrm{YC}$ - uracil and $\mathrm{EMM}+\mathrm{YC}+5$-FOA $(1 \mathrm{~g} / \mathrm{l})$, in which the concentration of uracil is $50.25 \mathrm{mg} / \mathrm{l}(\mathrm{EMM}+\mathrm{FOA})$. Cells that grew on $\mathrm{EMM}+\mathrm{YC}-$ uracil but not on EMM + FOA plates were inoculated in 96-well plates with $200 \mu \mathrm{l}$ of YES medium per well. As a second test for stable integration, selected transformants from each four 96-well plates were used to assemble 384-colony arrays on $\mathrm{EMM}+\mathrm{YC}$-uracil and $\mathrm{EMM}+\mathrm{FOA}$ Omni plates (Nalge Nunc International) using a 96-floating-pin replicator and a colony copier (VP409 and VP381, V\&P Scientific, Inc). Unstable transformants (i.e. cells that grew on EMM + FOA Omni 
plates) revealed in this step were removed from EMM + YC - uracil Omni plates.

Stable integrants that passed the second 5-FOA test were transferred to $40 \mu \mathrm{l}$ of $\mathrm{YES}+15 \%$ glycerol or $\mathrm{EMM}+\mathrm{YC}$ - uracil $+15 \%$ glycerol medium in 384-well plates using a 384-floating-pin replicator (VP386, V\&P Scientific, Inc) and incubated at $30^{\circ} \mathrm{C}$ for two days before being stored at $-80^{\circ} \mathrm{C}$. Cells left on each five EMM + $\mathrm{YC}$ - uracil Omni plates were scraped off and grown in a 250-ml flask with $50 \mathrm{ml}$ of EMM + YC - uracil medium for $4 \mathrm{~h}$ at $30^{\circ} \mathrm{C}$ before aliquots were frozen in the presence of $15 \%$ glycerol as mixed library pools.

\section{Determination of the size of S. pombe barcode-tagged insertion mutant library and bacterial barcode library}

We chose to generate $10,000 \mathrm{~S}$. pombe insertion mutants as a balance between the size of the yeast mutant library and the probability of obtaining a mutant in every protein coding gene, which was calculated by the sampling equation $\mathrm{P}=1-(1-\mathrm{f})^{\mathrm{N}}$ where $\mathrm{P}$ is the probability of finding any genes in the genome, $\mathrm{f}$ is the fraction of a gene in the genome (gene size/genome size) and $\mathrm{N}$ is the number of insertion mutants generated [65]. Assuming that an insertion in the 5, 3' regions of a gene, introns and exons can produce a mutant phenotype, and the average size of a $S$. pombe gene is $2 \mathrm{~kb}$ in a genome of $\sim 14,000 \mathrm{~kb}$, the probability of finding at least a mutation in each individual gene in 10,000 random mutants $\mathrm{P}$ is $1-(1-2 / 14,000)^{10,000}=0.76$ or $76 \%$.

To increase the probability of tagging individual $S$. pombe insertion mutants with unique, non-redundant barcodes, only 250 to $1,500 \mathrm{~S}$. pombe mutants were generated from each bacterial barcode sub-library, where the average number of barcode clones is $\sim 1.86 \times 10^{5}$. Thus, the number of $S$. pombe mutants generated from each sub-library corresponds to less than $1 \%$ of the available barcodes, and provides $\mathrm{a} \geq 95 \%$ chance that all of the barcodes are unique. A total of 18 bacterial sub-libraries were used to generate and tag 10,000 S. pombe insertion mutants.

\section{Barcode oligomerization}

Barcode DNA with flanking insertion vector sequences ( 760 bp) was amplified by PCR using genomic DNA prepared from fission yeast mutant cells in the library as the template, primers hsplam6 and BarcodePCR (888r), and the following program: initial denaturation for $3 \mathrm{~min}$ at $94^{\circ} \mathrm{C}$, then cycling 30 times with $40 \mathrm{~s}$ of denaturation $\left(94^{\circ} \mathrm{C}\right), 1 \mathrm{~min}$ of annealing $\left(60^{\circ} \mathrm{C}\right.$ for the first 10 cycles, $62^{\circ} \mathrm{C}$ for the last 20 cycles) and $1 \mathrm{~min}$ of extension $\left(72^{\circ} \mathrm{C}\right)$, and a final extension step of $7 \mathrm{~min}$ at $72^{\circ} \mathrm{C}$. After digestion of the PCR product with $S f i$ I enzyme, barcode DNA (66 bp) was separated from the two flanking DNA fragments ( 200 and $\sim 500 \mathrm{bp})$ on a $2 \%$ low melting agarose gel. The gel slice $(\sim 0.3 \times 2 \mathrm{~cm})$ containing the barcode DNA was melted at $65^{\circ} \mathrm{C}$ with $100 \mu \mathrm{l}$ of $1 \mathrm{X}$ TE and $70 \mu \mathrm{l}$ of $3 \mathrm{M}$ sodium acetate, $\mathrm{pH} 5.2$, and then extracted with $0.6 \mathrm{ml}$ of TE-saturated phenol. The aqueous phase was re-extracted with $0.6 \mathrm{ml}$ of phenol/chloroform/isoamyl alcohol, followed by extraction with $0.6 \mathrm{ml}$ of chloroform/ isoamyl alcohol. The final aqueous phase solution $(\sim 0.5 \mathrm{ml})$ was precipitated with $50 \mu \mathrm{l}$ of $3 \mathrm{M}$ sodium acetate, $\mathrm{pH} 5.2,1.1 \mathrm{ml}$ of $100 \%$ ethanol at $-80^{\circ} \mathrm{C}$ overnight and the precipitated DNA was washed with $1 \mathrm{ml}$ of $70 \%$ ethanol. The resulting barcode DNA was dissolved in $30 \mu \mathrm{l}$ of $10 \mathrm{mM}$ Tris- $\mathrm{HCl}, \mathrm{pH}$ 8.0. Barcode DNA $(\sim 1 \mu \mathrm{g})$ was oligomerized by T4 DNA ligase (used 600 units at the beginning of the reaction and adding another 400 units after $8 \mathrm{~h}$ ) with $15 \%$ polyethylene glycol (PEG) 3350 in a $20-\mu \mathrm{l}$ reaction at $16^{\circ} \mathrm{C}$ for $16 \mathrm{~h}$. The oligomerized barcode DNA was purified by QIAGEN PCR Purification kit to remove PEG and then resolved on a $2 \%$ low-melting agarose gel. Barcode oligomers with the size between 0.3 and $1 \mathrm{~kb}$ were purified using the method described above. The purified long barcode oligomers were ligated to $S f i$ I-digested and alkaline phosphatase (CIP)-treated pInsertion-ura4 vector and transformed to E. coli.

Bacterial transformants with large barcode inserts were first screened by extracting the total bacterial DNA from cells with phenol/chloroform/isoamyl alcohol and 1X DNA loading dye, and examining the aqueous phase, which contained bacterial genomic DNA and barcodecontaining plasmids, by agarose gel electrophoresis to compare the electrophoretic mobility of barcode insertcontaining plasmids (slow migrating) with the control plasmid without insert (pInsertion-ura4, fast migrating) on a $0.7 \%$ agarose gel. Plasmid DNA was purified from cells with large barcode inserts, verified by digestion with $B a m H$ I, and sequenced with primer TAIL-LB LOX71 to determine the barcode sequences.

\section{Genetic screens to assess mutation diversity}

Cells were first grown in $40 \mu \mathrm{l}$ of YES medium in 384well plates for two days. For the temperature sensitivity test, cells were transferred to two YES Omni plates, and one plate was incubated at $30^{\circ} \mathrm{C}$ and the other at $36^{\circ} \mathrm{C}$. Temperature-sensitive mutants were scored as those that grew normally at $30^{\circ} \mathrm{C}$ but not (or slowly) at $36^{\circ} \mathrm{C}$ after incubation for 4 days. To identify mutants with slow or no growth on minimal medium, cells were transferred to $\mathrm{EMM}+$ adenine, histidine, leucine and $\mathrm{EMM}+\mathrm{YC}-$ uracil Omni plates. Cells with auxotrophic mutations grew on $\mathrm{EMM}+\mathrm{YC}$ - uracil but not EMM + adenine, histidine, leucine plates. For the identification of adenine biosynthesis mutations, cells were transferred to YES with low adenine Omni plates to look for mutants with altered colony color. To isolate EtBr-resistant mutations, cells grown in YES liquid medium were first inoculated to $40 \mu \mathrm{l}$ of $\mathrm{YES}+2 \%$ potassium acetate $+12.5 \mathrm{mg} / \mathrm{l}$ of 
ethidium bromide (YES + EtBr) medium [12] in 384-well plates for 2 days before transfer to $\mathrm{YES}+\mathrm{EtBr}$ Omni plates. EtBr-resistant mutants were scored as the ability to grow on the YES $+\mathrm{EtBr}$ Omni plates. For the above three assays, cells were grown at $30^{\circ} \mathrm{C}$ for 5 days before scoring the phenotypes.

Mutants identified from the 384-colony array assays were individually verified by re-growing these mutants on the respective selective media or temperature as patches on regular Petri dish plates.

\section{Generation of pLox66 plasmid and integration of pLox66 to $S$. pombe strains bearing lox71 sequence}

The vector backbone was constructed by cutting pRS400 with Pac I and Sac II, rendering the ends blunt with Klenow enzyme and circularizing the vector by T4 DNA ligase. The double-strand lox66 DNA was generated by mixing and annealing oligonucleotides lox66_S and lox66_AS (25 $\mu \mathrm{M}$ each) on a thermal cycler by first denaturing at $95^{\circ} \mathrm{C}$ for three minutes and slow cooling from $95^{\circ} \mathrm{C}$ to $20^{\circ} \mathrm{C}\left(-0.5^{\circ} \mathrm{C}\right.$ per cycle for 150 cycles with each cycle/temperature lasting for one minute). The resulting double strand DNA was ligated to the Aat II and $B s a$ I sites of pRS400 $\Delta \mathrm{PacI} / \mathrm{SacII}$ (which deleted the ampicillin resistance gene) to generate the plasmid pLox66 (Additional file 10).

To integrate pLox66 into $S$. pombe cells bearing a chromosomal lox71 site, insertion mutant cells were first preloaded with Cre recombinase by transforming cells with pREP81-Cre [66] and growing transformed cells in EMM medium with $225 \mathrm{mg} / \mathrm{l}$ of adenine and histidine for $48 \mathrm{~h}$. Cre recombinase-expressing cells were then transformed with pLox66 and maintained on solid EMM medium at $30^{\circ} \mathrm{C}$ for $24 \mathrm{~h}$, followed by replica plating these cells to YES + G418 (200 mg/l) to select for cells with stably integrated pLox66.

\section{Identification of insertion sites by thermal asymmetric interlaced (TAIL)-PCR}

TAIL-PCR was conducted as described in Singer and Burke [41]. Briefly, three rounds of PCR, using alternate annealing temperatures, degenerate primers (TAIL AD1-6) and one of the three nested specific primers, TAIL LB2, TAIL lox71 and hsplam3 (or InversePCR1, InversePCR 3 and InversePCR 2), in each round, yielded one or a few bands in the tertiary PCR (Additional file 3: Figure S2A). The primary PCR used the genomic DNA of $S$. pombe insertion mutants as the template. One $\mu \mathrm{l}$ of 50 -fold diluted products from the primary and the secondary PCR was used as the template in the secondary and the tertiary PCR, respectively. TAIL-PCR products were treated with exonuclease I and shrimp alkaline phosphatase (Exo-SAP, USB) or purified by QIAGEN
Gel Extraction Kit prior to sequencing. The products from the secondary and the tertiary PCR were sequenced with primers hsplam5 and hsplam7 (or InversePCR 3 and InversePCR 2), respectively.

\section{Identification of insertion sites by splinkerette PCR}

Splinkerette PCR was carried out as described in $[42,44]$. Briefly, a double-stranded splinkerette adaptor with a hairpin-forming sequence and a Spe $\mathrm{I} / \mathrm{Xba}$ I overhang was made by annealing oligos SPLK_A and SPLK_B_SpeI/XbaI on a thermal cycler by first denaturing at $95^{\circ} \mathrm{C}$ for three minutes and slow cooling from $95^{\circ} \mathrm{C}$ to $20^{\circ} \mathrm{C}\left(-0.5^{\circ} \mathrm{C}\right.$ per cycle for 150 cycles with each cycle/temperature lasting for one minute). The splinkerette adaptor was ligated to genomic DNA digested with Spe I and Xba I, and the ligation product was used as the template in the first PCR reaction with primers SPLKFwd_1 and hsplam3. One $\mu \mathrm{l}$ of the 50-fold diluted first PCR product was used as the template in the second PCR with primers SPLKFwd_2 and hsplam5. The product generated in the second PCR reaction was sequenced by SPLKFwd_2 or hsplam 5 .

Identification of insertion sites by inverse splinkerette PCR Genomic DNA $(10 \mu \mathrm{g})$ was digested with 80 units of EcoR V-HF (NEB) at $37^{\circ} \mathrm{C}$ for $16 \mathrm{~h}$, followed by $65^{\circ} \mathrm{C}$ denaturation for $15 \mathrm{~min}$. A total of $1.5 \mu \mathrm{g}$ of digested DNA was used in a 500- $\mu$ l ligation (final DNA concentration $=3 \mathrm{ng} / \mu \mathrm{l}$ ) with 2000 units of $\mathrm{T} 4$ DNA ligase at $16^{\circ} \mathrm{C}$ for $16 \mathrm{~h}$. Ligated DNA was subsequently digested with 60 units of $S f i$ I restriction endonuclease at $50^{\circ} \mathrm{C}$ for five hours. All of the $S f i$ Idigested DNA was used in a $30-\mu$ l ligation reaction that contained $0.33 \mu \mathrm{M}$ of double-strand $S f i$ I splinkerette and 800 units of T4 DNA ligase. The doublestrand $S f i$ I splinkerette DNA was generated as described in the splinkerette PCR by annealing oligonucleotides Sfi I SPLK_A_GGG and Sfi I SPLK_B. After incubation at $16^{\circ} \mathrm{C}$ for $16 \mathrm{~h}$, the ligation mixture was purified by phenol/chloroform extraction and ethanol precipitation as described above and resuspended in $10 \mu \mathrm{l}$ of $10 \mathrm{mM}$ Tris, $\mathrm{pH}$ 8.0.

To amplify genomic DNA flanked by Sfi I splinkerette and the $\mathrm{ura}^{+}$selectable marker, two rounds of PCR were carried out. In the first PCR, one $\mu$ l of purified ligation product was used as the template with InvU4_1366F and SPLKFwd_1 primers. In the second PCR, one $\mu \mathrm{l}$ of 50 -fold diluted first PCR product was used as the template with Ura4_EcoR V and SPLKFwd_2 primers. Products from the second PCR reaction were purified by QIAGEN Gel Purification Kit and sequenced by the primer Ura4_EcoR V. 


\section{Additional files}

Additional file 1: Figure S1. A strategy to enrich for cells that have few copies of the $\mathrm{ura}^{+}$gene. Based on a hypothetical metabolic outcome of altered Ura4 protein levels and low concentrations of 5-FOA on cell survival, cells bearing few or many copies of $\mathrm{ura}^{+}$genes are expected to exhibit different sensitivities to 5-FOA. (A) In cells with multiple copies of the $\mathrm{ura}^{+}$gene, increased levels of Ura4 allow efficient conversion of low dose of 5-FOA to toxic 5-fluorouracil. These cells die in the medium supplied with a low concentration of 5-FOA (i.e. $0.1 \mathrm{~g} / \mathrm{l}$, data not shown). (B) In cells bearing a small number of copies of the $\mathrm{ura}^{+}$gene, endogenous orotidine-5-phosophate (orotidine-5P) may outcompete 5FOA supplied in low concentrations as the preferred substrate of the limited amount of Ura4, prevent Ura4 from metabolizing 5-FOA to 5fluorouracil and allow such cells to grow in medium with low 5-FOA.

Additional file 2: Table S1. Tetrad analysis and insertion site mapping of $S$. pombe barcoded insertion mutants.

Additional file 3: Figure S2. Characterization of insertion events by thermal asymmetric interlaced (TAIL)-PCR. (A) In mutants with a single or very few copies of insertion vectors, DNA fragments composed of partial insertion vector sequences and adjacent genomic DNA sequences could be amplified using vector-specific primers and a mixture of arbitrary degenerate (AD) primers. The nested vector-specific primers in each round of PCR reactions allowed for amplification of the final PCR products with increasing specificity. (B) In the event of tandem integration of multiple copies of the insertion vector, TAlL-PCR often resulted in amplification within insertion vectors due to additional binding sites for AD primers in the additional copies of insertion vectors. When vectors were integrated in head-to-head orientation, vector-specific primers could bind both strands of the repetitive insertion vector DNA and only amplify the vector sequences. (C) Mitochondrial DNA was found co-integrated with the insertion vector into the genome in some mutants. In such mutants, TAIL-PCR could only amplify DNA sequences corresponding to the insertion vector and mitochondrial DNA, which might result from additional binding site for AD primers in mitochondrial DNA.

Additional file 4: Figure S3. Characterization of insertion events by splinkerette PCR. In splinkerette PCR, genomic DNA is first digested with restriction enzymes that do not cut or cut very few times in the insertion vector (e.g. Xba I and Spe I, or BCl I and Bgl II). Double strand splinkerette adaptor DNA can then be ligated to the digested genomic DNA with compatible overhangs. The resulting products, genomic fragments flanked by splinkerette and insertion vector DNA, can be amplified by PCR using primers on splinkerette (solid arrows) and the insertion vector (dashed arrows).

Additional file 5: Table S2. Insertion events with both insertiongenomic junctions characterized.

Additional file 6: Potential modes of integration of non-homologous DNA in S. pombe genome. After being transfected into S. pombe cells, non-homologous DNA could be integrated into the genome as a single copy. In some cases, the ends of non-homologous DNA may be first deleted by nucleolytic activities in cells and then ligated to other linear DNA fragments in head-to-tail, heat-to-head or tail-to-tail orientations before being integrated in the genome.

Additional file 7: Table S3. The amino acid and nucleobase supplements in the minimum medium $+Y C$ - uracil.

Additional file 8: Table S4. Oligonucleotides used in this study.

Additional file 9: plnsertion-ura4. Annotated sequence of

plnsertion-ura4.

Additional file 10: pLox66. Annotated sequence of pLox66.

\section{Competing interests}

The authors declare that they have no competing interests.

\section{Acknowledgements}

The authors thank Dr. Nancy Kleckner for providing the pREP81-Cre plasmid Anna Yakubenko and Rebecca Shtofman for technical assistance, and Drs. Steven Sanders and S. Elizabeth Hulme Berezovsky for critical reading and comments on the manuscript. This work was funded by $\mathrm{NIH}$ grant R01AG019960 to KWR.

\section{Author details}

'Department of Genetics, Case Western Reserve University School of Medicine, 10900 Euclid Avenue, Cleveland, OH 44106, USA. ${ }^{2}$ Department of Molecular Genetics, Cleveland Clinic Lerner College of Medicine at CWRU, 9500 Euclid Avenue, NE20, Cleveland, OH 44195, USA. ${ }^{3}$ John Carroll University, 20700 North Park Boulevard, University Heights, Ohio 44118, USA. ${ }^{4}$ Miami University, 501 East High Street, Oxford, OH 45056, USA. ${ }^{5}$ Current address: West Virginia School of Osteopathic Medicine, 400 North Lee Street, Lewisburg, WV 24901, USA. ${ }^{6}$ Current address: College of Medicine, Ohio State University, 370 West 9th Avenue, Columbus, OH 43210, USA.

\section{Authors' contributions}

$\mathrm{B}-\mathrm{RC}$ and KWR designed the research project. B-RC, DCH and PJC carried out experiments. B-RC and KWR analyzed the data and wrote the manuscript. All authors have read and approved the final manuscript.

Received: 2 November 2011 Accepted: 3 May 2012

Published: 3 May 2012

\section{References}

1. Schena M, Shalon D, Davis RW, Brown PO: Quantitative monitoring of gene expression patterns with a complementary DNA microarray. Science 1995, 270(5235):467-470

2. Giaever G, Chu AM, Ni L, Connelly C, Riles L, Veronneau S, Dow S, Lucau-Danila A, Anderson K, Andre B, et al: Functional profiling of the Saccharomyces cerevisiae genome. Nature 2002, 418(6896):387-391.

3. Hensel M, Shea JE, Gleeson C, Jones MD, Dalton E, Holden DW: Simultaneous identification of bacterial virulence genes by negative selection. Science 1995, 269(5222):400-403.

4. Shoemaker DD, Lashkari DA, Morris D, Mittmann M, Davis RW: Quantitative phenotypic analysis of yeast deletion mutants using a highly parallel molecular bar-coding strategy. Nat Genet 1996, 14(4):450-456.

5. Singhi AD, Kondratov RV, Neznanov N, Chernov MV, Gudkov AV: Selection-subtraction approach (SSA): a universal genetic screening technique that enables negative selection. Proc Natl Acad Sci U S A 2004, 101(25):9327-9332

6. Ngo VN, Davis RE, Lamy L, Yu X, Zhao H, Lenz G, Lam LT, Dave S, Yang L, Powell J, et al: A loss-of-function RNA interference screen for molecular targets in cancer. Nature 2006, 441(7089):106-110.

7. Winzeler EA, Shoemaker DD, Astromoff A, Liang H, Anderson K, Andre B, Bangham R, Benito R, Boeke JD, Bussey H, et al: Functional characterization of the $S$. cerevisiae genome by gene deletion and parallel analysis. Science 1999, 285(5429):901-906.

8. Fabrizio P, Hoon S, Shamalnasab M, Galbani A, Wei M, Giaever G, Nislow C, Longo VD: Genome-wide screen in Saccharomyces cerevisiae identifies vacuolar protein sorting, autophagy, biosynthetic, and tRNA methylation genes involved in life span regulation. PLOS Genet 2010, 6(7):e1001024.

9. Matecic M, Smith DL, Pan X, Maqani N, Bekiranov S, Boeke JD, Smith JS: A microarray-based genetic screen for yeast chronological aging factors. PLoS Genet 2010, 6(4):e1000921.

10. Wood V, Gwilliam R, Rajandream MA, Lyne M, Lyne R, Stewart A, Sgouros J, Peat N, Hayles J, Baker S, et al: The genome sequence of Schizosaccharomyces pombe. Nature 2002, 415(6874):871-880.

11. Forsburg SL, Rhind N: Basic methods for fission yeast. Yeast 2006, 23 (3):173-183.

12. Haffter P, Fox TD: Nuclear mutations in the petite-negative yeast Schizosaccharomyces pombe allow growth of cells lacking mitochondrial DNA. Genetics 1992, 131(2):255-260.

13. Kaufer NF, Potashkin J: Analysis of the splicing machinery in fission yeast: a comparison with budding yeast and mammals. Nucleic Acids Res 2000, 28(16):3003-3010.

14. Kaufer NF, Simanis $V$, Nurse P: Fission yeast Schizosaccharomyces pombe correctly excises a mammalian RNA transcript intervening sequence. Nature 1985, 318(6041):78-80.

15. Shuster EO, Guthrie C: Human U2 snRNA can function in pre-mRNA splicing in yeast. Nature 1990, 345(6272):270-273. 
16. Volpe TA, Kidner C, Hall IM, Teng G, Grewal SI, Martienssen RA: Regulation of heterochromatic silencing and histone $\mathrm{H} 3$ lysine- 9 methylation by RNAi. Science 2002, 297(5588):1833-1837.

17. Kim DU, Hayles J, Kim D, Wood V, Park HO, Won M, Yoo HS, Duhig T, Nam M, Palmer $G$, et al: Analysis of a genome-wide set of gene deletions in the fission yeast Schizosaccharomyces pombe. Nat Biotechnol 2010, 28(6):617-623.

18. Smith JS, Caputo E, Boeke JD: A genetic screen for ribosomal DNA silencing defects identifies multiple DNA replication and chromatin-modulating factors. Mol Cell Biol 1999, 19(4):3184-3197.

19. Curran SP, Ruvkun G: Lifespan regulation by evolutionarily conserved genes essential for viability. PLoS Genet 2007, 3(4):e56.

20. Chua G, Taricani L, Stangle W, Young PG: Insertional mutagenesis based on illegitimate recombination in Schizosaccharomyces pombe. Nucleic Acids Res 2000, 28(11):E53.

21. Davidson MK, Young NP, Glick GG, Wahls WP: Meiotic chromosome segregation mutants identified by insertional mutagenesis of fission yeast Schizosaccharomyces pombe; tandem-repeat, single-site integrations. Nucleic Acids Res 2004, 32(14):4400-4410.

22. Schuldiner M, Collins SR, Thompson NJ, Denic V, Bhamidipati A, Punna T, Ihmels J, Andrews B, Boone C, Greenblatt JF, et al: Exploration of the function and organization of the yeast early secretory pathway through an epistatic miniarray profile. Cell 2005, 123(3):507-519.

23. Muhlrad D, Parker R: Aberrant mRNAs with extended 3' UTRs are substrates for rapid degradation by mRNA surveillance. RNA 1999, 5 (10):1299-1307.

24. Grimm C, Kohli J: Observations on integrative transformation in Schizosaccharomyces pombe. Mol Gen Genet 1988, 215(1):87-93.

25. Tatebayashi K, Kato J, Ikeda H: Structural analyses of DNA fragments integrated by illegitimate recombination in Schizosaccharomyces pombe. Mol Gen Genet 1994, 244(2):111-119.

26. Decottignies A: Capture of extranuclear DNA at fission yeast double-strand breaks. Genetics 2005, 171(4):1535-1548.

27. Boeke JD, LaCroute F, Fink GR: A positive selection for mutants lacking orotidine-5'-phosphate decarboxylase activity in yeast: 5-fluoro-orotic acid resistance. Mol Gen Genet 1984, 197(2):345-346.

28. Grimm C, Kohli J, Murray J, Maundrell K: Genetic engineering of Schizosaccharomyces pombe: a system for gene disruption and replacement using the ura4 gene as a selectable marker. Mol Gen Genet 1988, 215(1):81-86.

29. Prentice $H L$, Kingston RE: Mammalian promoter element function in the fission yeast Schizosaccharomyces pombe. Nucleic Acids Res 1992, 20(13):3383-3390.

30. Walker GC: Mutagenesis and inducible responses to deoxyribonucleic acid damage in Escherichia coli. Microbiol Rev 1984, 48(1):60-93.

31. Araki $K$, Araki M, Yamamura K: Targeted integration of DNA using mutant lox sites in embryonic stem cells. Nucleic Acids Res 1997, 25(4):868-872.

32. Vojtek AB, Hollenberg SM, Cooper JA: Mammalian Ras interacts directly with the serine/threonine kinase Raf. Cell 1993, 74(1):205-214.

33. Schizosaccharomyces pombe GeneDB. [http://old.genedb.org/amigo-cgi/ browse.cgi?speciesdb=GeneDB_Spombe].

34. Dujon B: Mitochondrial genetics and functions. In The Molecular Biology of the Yeast Saccharomyces. Edited by Strathern JN, Jones EW, Broach JR. Cold Spring Harbor, NY: Cold Spring Harbor Laboratory Press; 1981:505-635.

35. Kim G, Sikder $H$, Singh KK: A colony color method identifies the vulnerability of mitochondria to oxidative damage. Mutagenesis 2002, 17 (5):375-381.

36. Kyoto Encyclopedia of Genes and Genomes. [http://www.genome.jp/ $\mathrm{kegg} /$.

37. King MP, Attardi G: Human cells lacking mtDNA: repopulation with exogenous mitochondria by complementation. Science 1989, 246(4929):500-503.

38. Saccharomyces Genome Deletion Project. [http://www-sequence.stanford. edu/group/yeast_deletion_project/project_desc.html].

39. Stansfield I, Stark MJR: Yeast Gene Analysis.: Elsevier Academic Press; 2007.

40. Liu YG, Whittier RF: Thermal asymmetric interlaced PCR: automatable amplification and sequencing of insert end fragments from P1 and YAC clones for chromosome walking. Genomics 1995, 25(3):674-681.

41. Singer T, Burke E: High-throughput TAIL-PCR as a tool to identify DNA flanking insertions. Methods Mol Biol 2003, 236:241-272.
42. Horn C, Hansen J, Schnutgen F, Seisenberger C, Floss T, Irgang M, De-Zolt S, Wurst W, von Melchner H, Noppinger PR: Splinkerette PCR for more efficient characterization of gene trap events. Nat Genet 2007, 39(8):933-934.

43. Uren AG, Mikkers $H$, Kool J, van der Weyden L, Lund AH, Wilson CH, Rance $\mathrm{R}$, Jonkers J, van Lohuizen M, Berns $A$, et al: A high-throughput splinkerette-PCR method for the isolation and sequencing of retroviral insertion sites. Nat Protoc 2009, 4(5):789-798.

44. Devon RS, Porteous DJ, Brookes AJ: Splinkerettes-improved vectorettes for greater efficiency in PCR walking. Nucleic Acids Res 1995, 23(9):1644-1645.

45. Roguev A, Wiren M, Weissman JS, Krogan NJ: High-throughput genetic interaction mapping in the fission yeast Schizosaccharomyces pombe. Nature methods 2007, 4(10):861-866.

46. Tong AH, Evangelista M, Parsons AB, Xu H, Bader GD, Page N, Robinson M, Raghibizadeh S, Hogue CW, Bussey H, et al: Systematic genetic analysis with ordered arrays of yeast deletion mutants. Science 2001, 294 (5550):2364-2368.

47. Gottschling DE, Aparicio OM, Billington BL, Zakian VA: Position effect at S. cerevisiae telomeres: reversible repression of Pol II transcription. Cell 1990, 63(4):751-762.

48. Lenglez S, Hermand D, Decottignies A: Genome-wide mapping of nuclear mitochondrial DNA sequences links DNA replication origins to chromosomal double-strand break formation in Schizosaccharomyces pombe. Genome Res 2010, 20(9):1250-1261.

49. Behura SK: Analysis of nuclear copies of mitochondrial sequences in honeybee (Apis mellifera) genome. Molecular biology and evolution 2007, 24(7):1492-1505.

50. Pamilo P, Viljakainen L, Vihavainen A: Exceptionally high density of NUMTs in the honeybee genome. Molecular biology and evolution 2007, 24 (6):1340-1346.

51. Cheng $X$, Ivessa AS: The migration of mitochondrial DNA fragments to the nucleus affects the chronological aging process of Saccharomyces cerevisiae. Aging Cell 2010, 9(5):919-923.

52. Sacerdot C, Casaregola S, Lafontaine I, Tekaia F, Dujon B, Ozier-Kalogeropoulos O: Promiscuous DNA in the nuclear genomes of hemiascomycetous yeasts. FEMS Yeast Res 2008, 8(6):846-857.

53. Hazkani-Covo E, Zeller RM, Martin W: Molecular poltergeists: mitochondrial DNA copies (numts) in sequenced nuclear genomes. PLoS Genet 2010, 6 (2):e1000834.

54. Triant DA, DeWoody JA: Molecular analyses of mitochondrial pseudogenes within the nuclear genome of arvicoline rodents. Genetica 2008, 132(1):21-33.

55. Noutsos C, Richly E, Leister D: Generation and evolutionary fate of insertions of organelle DNA in the nuclear genomes of flowering plants. Genome Res 2005, 15(5):616-628.

56. Guo Y, Levin HL: High-throughput sequencing of retrotransposon integration provides a saturated profile of target activity in Schizosaccharomyces pombe. Genome Res 2010, 20(2):239-248.

57. Li J, Zhang JM, Li X, Suo F, Zhang MJ, Hou W, Han J, Du LL: A piggyBac transposon-based mutagenesis system for the fission yeast Schizosaccharomyces pombe. Nucleic Acids Res 2011, 39(6):e40.

58. Evertts AG, Plymire C, Craig NL, Levin HL: The hermes transposon of Musca domestica is an efficient tool for the mutagenesis of Schizosaccharomyces pombe. Genetics 2007, 177(4):2519-2523.

59. Chen BR, Runge KW: A new Schizosaccharomyces pombe chronological lifespan assay reveals that caloric restriction promotes efficient cell cycle exit and extends longevity. Exp Gerontol 2009, 44(8):493-502.

60. Apolinario E, Nocero M, Jin M, Hoffman CS: Cloning and manipulation of the Schizosaccharomyces pombe his7+ gene as a new selectable marker for molecular genetic studies. Curr Genet 1993, 24(6):491-495.

61. Moreno S, Klar A, Nurse P: Molecular Biology of the Fission Yeast Schizosacchromyces pombe. MethEnzym 1991, 194:795-823.

62. PombeNet. [http://www-bcf.usc.edu/ forsburg/drugs.html\#FOA].

63. Hirashima K, Iwaki T, Takegawa K, Giga-Hama Y, Tohda H: A simple and effective chromosome modification method for large-scale deletion of genome sequences and identification of essential genes in fission yeast. Nucleic Acids Res 2006, 34(2):e11.

64. Suga $M$, Hatakeyama $T$ : A rapid and simple procedure for high-efficiency lithium acetate transformation of cryopreserved Schizosaccharomyces pombe cells. Yeast 2005, 22(10):799-804. 
65. Sambrook J, Russell DW: Molecular Cloning-A laboratory manual. vol. 1, 3rd edition. Cold Spring Harbor, New York: Cold Spring Harbor Laboratory Press; 2001.

66. Molnar M, Kleckner N: Examination of interchromosomal interactions in vegetatively growing diploid Schizosaccharomyces pombe cells by Cre/ loxP site-specific recombination. Genetics 2008, 178(1):99-112.

doi:10.1186/1471-2164-13-161

Cite this article as: Chen et al:: Generation and analysis of a barcode-

tagged insertion mutant library in the fission yeast Schizosaccharomyces pombe. BMC Genomics 2012 13:161.

\section{Submit your next manuscript to BioMed Central} and take full advantage of:

- Convenient online submission

- Thorough peer review

- No space constraints or color figure charges

- Immediate publication on acceptance

- Inclusion in PubMed, CAS, Scopus and Google Scholar

- Research which is freely available for redistribution 